\title{
Isoform-Specific Reduction of the Basic Helix-Loop-Helix Transcription Factor TCF4 Levels in Huntington's Disease
}

\author{
Kaja Nurm, ${ }^{1}$ Mari Sepp, ${ }^{1}$ Carla Castany-Pladevall,, ${ }^{3,4,5}$ Jordi Creus-Muncunill, ${ }^{3,4,5}$ (Jürgen Tuvikene, ${ }^{1,2}$ \\ Alex Sirp, ${ }^{1}$ Hanna Vihma, ${ }^{1}$ DDerek J. Blake, ${ }^{6}$ Esther Perez-Navarro, ${ }^{3,4,5}$ and Tõnis Timmusk ${ }^{1,2}$
}

https://doi.org/10.1523/ENEURO.0197-21.2021

${ }^{1}$ Department of Chemistry and Biotechnology, Tallinn University of Technology, Tallinn 12618, Estonia, ${ }^{2}$ Protobios LLC, Tallinn 12618, Estonia, ${ }^{3}$ Departament de Biomedicina, Facultat de Medicina i Ciències de la Salut, Institut de Neurociències, Universitat de Barcelona, Barcelona, Catalonia 08036, Spain, ${ }^{4}$ Institut d'Investigacions Biomèdiques August Pi i Sunyer (IDIBAPS), Barcelona, Catalonia 08036, Spain, ${ }^{5}$ Centro de Investigación Biomédica en Red sobre Enfermedades Neurodegenerativas (CIBERNED), Madrid, 28031, Spain, and ${ }^{6}$ Division of Psychological Medicine and Clinical Neurosciences, MRC Centre for Neuropsychiatric Genetics and Genomics, Cardiff University, Cardiff CF24 $4 \mathrm{HQ}$, United Kingdom

\begin{abstract}
Huntington's disease (HD) is an inherited neurodegenerative disorder with onset of characteristic motor symptoms at midlife, preceded by subtle cognitive and behavioral disturbances. Transcriptional dysregulation emerges early in the disease course and is considered central to HD pathogenesis. Using wild-type (wt) and HD knock-in mouse striatal cell lines we observed a HD genotype-dependent reduction in the protein levels of transcription factor 4 (TCF4), a member of the basic helix-loop-helix (bHLH) family with critical roles in brain development and function. We characterized mouse Tcf4 gene structure and expression of alternative mRNAs and protein isoforms in cell-based models of HD, and in four different brain regions of male transgenic HD mice (R6/1) from young to mature adulthood. The largest decrease in the levels of TCF4 at mRNA and specific protein isoforms were detected in the R6/1 mouse hippocampus. Translating this finding to human disease, we found reduced expression of long TCF4 isoforms in the postmortem hippocampal CA1 area and in the cerebral cortex of HD patients. Additionally, TCF4 protein isoforms showed differential synergism with the proneural transcription factor ASCL1 in activating reporter gene transcription in hippocampal and cortical cultured neurons. Induction of neuronal activity increased these synergistic effects in hippocampal but not in cortical neurons, suggesting brain region-dependent differences in TCF4 functions. Collectively, this study demonstrates isoform-specific changes in TCF4 expression in HD that could contribute to the progressive impairment of transcriptional regulation and neuronal function in this disease.
\end{abstract}

\section{Significance Statement}

Historically, Huntington's disease (HD) has been considered a neurodegenerative disease. However, research of the last decade has revealed disrupted neurogenesis and cognitive dysfunction preceding pathologic neuronal cell death, suggesting that HD is also a neurodevelopmental disease. One of the major molecular mechanisms of HD is dysregulation of transcription. Studying transcription factors with functions in neurogenesis and neural plasticity is of interest for their potential participation in the cognitive impairment in HD etiology. Here, we show reduced expression of the transcription factor TCF4, previously linked with neurodevelopmental and neuropsychiatric diseases, in hippocampus and cerebral cortex of R6/1 mouse and HD patients. Our results shed light on the potential neurodevelopmental aspect of HD and could be applicable for developing alleviating therapies for HD. 
Key words: basic helix-loop-helix transcription factor; Huntington's disease; neurodegenerative disease; TCF4; transcriptional regulation

\section{Introduction}

Huntington's disease (HD; OMIM \#143100) is a fatal inherited neurodegenerative disorder caused by autosomal dominant mutation in the huntingtin (HTT) gene (The Huntington's Disease Collaborative Research Group, 1993). The mutation is a trinucleotide repeat $(C A G)_{n}$ expansion in $H T T$ exon 1, leading to translation of abnormal HTT protein with expanded polyglutamine tract in its $\mathrm{N}$ terminus. To study the disease mechanisms, different HD models have been developed, including chemically induced models using mitochondrial toxin 3-nitropropionic acid (3-NP) and genetic models in various cell-based systems and animals (for review, see Pouladi et al., 2013).

Clinically, HD is characterized by chorea and impairment of voluntary movements caused by striatal and cortical neurodegeneration that are preceded by cognitive and psychiatric disturbances (Stout et al., 2011). However, based on the critical functions of HTT in the developing nervous system a developmental basis for HD has been also proposed (Zuccato and Cattaneo, 2014; Bates et al., 2015). In fact, human and mouse embryos carrying mutant $H T T$ show clear abnormalities in the developing cortex, including defects in neural progenitor differentiation and cell cycle progression (Barnat et al., 2020). Moreover, carriers of mutant HTT gene have changes in the striatum (van der Plas et al., 2019) and

Received May 3, 2021; accepted August 22, 2021; First published September 13, 2021.

The authors declare no competing financial interests.

Author contributions: K.N., M.S., J.T., and T.T. designed research; K.N., M.S., C.C.-P., J.C.-M., A.S., and H.V. performed research; K.N., M.S., C.C.-P., J.C.-M., J.T., A.S., H.V., D.J.B., E.P.-N., and T.T. analyzed data; K.N., M.S., J.T., D.J.B., E.P.-N., and T.T. wrote the paper.

This work was supported by the Estonian Research Council Institutional Research Funding IUT19-18 and Grant PRG805, the European Union through the European Regional Development Fund Project No. 2014-2020.4.01.15-0012, H2020-MSCA-RISE-2016 (Grant EU734791), and the Spanish government through the Spanish Ministry of Science, Innovation and Universities Grant PID2019106447RB-100 (to E.P.-N.). D.J.B. was supported by the Medical Research Council (MRC) Grant MR/L010305/1. This work has also been partially supported by "TUT Institutional Development Program for 2016-2022" Graduate School in clinical medicine receiving funding from the European Regional Development Fund under Program ASTRA 2014-2020.4.01.16-0032 in Estonia.

M. Sepp's present address: Center for Molecular Biology of Heidelberg University (ZMBH), Heidelberg D-69120, Germany.

H. Vihma's present address: Department of Cell Biology and Physiology, Neuroscience Center, University of North Carolina, Chapel Hill, NC 27599.

J. Creus-Muncunill's present address: Department of Neurology, Icahn School of Medicine at Mount Sinai, New York, NY 10029.

Acknowledgements: We thank Elena Cattaneo for support and feedback in the early stage of this study; Epp Väli, Ana López, and M. Teresa Muñoz for technical assistance; and Kaisa Roots for cloning construct pGL4.83[hRlucP/ PGK1/Puro].

Correspondence should be addressed to Tõnis Timmusk at tonis. timmusk@taltech.ee.

https://doi.org/10.1523/ENEURO.0197-21.2021

Copyright @ 2021 Nurm et al.

This is an open-access article distributed under the terms of the Creative Commons Attribution 4.0 International license, which permits unrestricted use, distribution and reproduction in any medium provided that the original work is properly attributed. cerebellum (Tereshchenko et al., 2020) at presymptomatic stages.

In healthy adults, cognitive functions such as learning and memory rely on neuronal plasticity and neurogenesis in the hippocampus and cerebral cortex (McClelland et al., 1995; Chambers et al., 2004; Aimone et al., 2009; Gonçalves et al., 2016; Mansvelder et al., 2019). While atrophy and neurodegeneration in striatum and cerebral cortex is a neuropathological hallmark of HD, the hippocampus remains relatively unaffected in HD patients (Ramirez-Garcia et al., 2020), although misregulated transcriptional pathway of synaptic vesicles has been observed (Neueder and Bates, 2014). On the other hand, reduced hippocampal adult neurogenesis in subgranular zone (SGZ) of the dentate gyrus (DG) has been reported in $\mathrm{R} 6 / 2, \mathrm{R} 6 / 1$, and YAC128 HD mouse models (Lazic et al., 2004; Gil et al., 2005; Simpson et al., 2011) and Q175FDN knock-in HD mice show deficits in hippocampal synaptic plasticity (Quirion and Parsons, 2019).

Transcriptional dysregulation is a well-characterized molecular mechanism in HD pathophysiology (for review, see Sugars and Rubinsztein, 2003; Cha, 2007; Valor, 2015). Mutant HTT has been shown to bind and disrupt the functions of general transcription factors and transcriptional regulators in HD (Dunah et al., 2002; LuthiCarter et al., 2002; Bae et al., 2005; Zhai et al., 2005) and has impaired capacity to interact with RE1-silencing transcription factor/neuron-restrictive silencer factor (REST/ NRSF), which alters the expression of many neuronal genes including brain-derived neurotrophic factor (BDNF; Zuccato et al., 2003, 2007). Furthermore, the global transcriptional dysregulation in HD has been refined in genomics, proteomics and network analysis studies (Langfelder et al., 2016; Hensman Moss et al., 2017; Ament et al., 2018).

Transcription factor 4 (TCF4) belongs to a large bHLH transcription factor family and is a dimerization partner to other bHLH proteins for binding to E-box sequences of target genes (for review, see Massari and Murre, 2000). Importantly, TCF4 should not be confused with key factor of Wnt signaling pathway TCF7L2, unofficially called TCF4. TCF4 is widely but not equally expressed in human brain and the use of numerous alternative $5^{\prime}$ exons leads to generation of many different TCF4 protein isoforms (Sepp et al., 2011). TCF4 regulates many genes implicated in neurodevelopment, ion channel functions and signal transduction (Forrest et al., 2018). Furthermore, TCF4 regulates synaptic plasticity and memory, and overexpression of TCF4 results in abnormal distribution of layer 2/3 pyramidal neurons in prefrontal cortex and alters their intrinsic excitability (Kennedy et al., 2016; Page et al., 2018; Thaxton et al., 2018). A recent study by Tamberg and colleagues (Tamberg et al., 2020) showed that reduction of Daughterless (Drosophila melanogaster homolog of TCF4) in larvae central nervous system impairs appetitive associative learning and downregulates synaptic protein encoding genes, 
therefore linking Daughterless, and possibly TCF4, to memory formation (Tamberg et al., 2020).

Our immunocytochemical screen of different transcription factors in a cellular model of HD revealed differential expression and/or localization of TCF4. Therefore, based on the developmental hypothesis as well as disturbed synaptic plasticity and adult neurogenesis in HD, we decided to thoroughly investigate the expression of neurodevelopmentally important TCF4 in cellular and mouse models of HD and in HD patients. We show that TCF4 levels are reduced in HD brain in an isoform-dependent and brain region-dependent manner. We further reveal differences in the ability of different TCF4 isoforms to cooperate with Class II bHLH transcription factor ASCL1 in neurons. These results implicate reduced and/or imbalanced TCF4 function as a possible factor in HD etiology.

\section{Materials and Methods}

\section{Cell culture}

The striatal progenitor $\mathrm{Hdh}^{7 / 7}, \mathrm{Hdh}^{7 / 109}$, and $\mathrm{Hdh}^{109 / 109}$ cell lines have been described previously (Zuccato et al., 2003). Briefly, $\mathrm{Hdh}^{7 / 7}$ cells are derived from wild-type (wt) mice carrying two copies of the endogenous $\mathrm{Htt}$ alleles with 7 CAG repeats; $\mathrm{Hdh}^{7 / 109}$ and $\mathrm{Hdh}^{109 / 109}$ are derived from heterozygous and homozygous knock-in mice with one or both $\mathrm{Htt}$ alleles containing $109 \mathrm{CAG}$ repeats, respectively. Hdh cells were propagated in DMEM (Invitrogen) supplemented with 10\% fetal bovine serum (PAA Laboratories), $100 \mathrm{U} / \mathrm{ml}$ penicillin and $0.1 \mathrm{mg} / \mathrm{ml}$ streptomycin (PAA Laboratories) at $33^{\circ} \mathrm{C}$ in $5 \% \mathrm{CO}_{2}$.

Separate rat cortical and hippocampal neuronal cultures were prepared from embryonic day (E) 21 Sprague Dawley rat embryos as described previously (Esvald et al., 2020). Where indicated, neurons were treated with 0.5 mm 3-NP (Sigma-Aldrich) for 0-16 h at 6-8 days in vitro (DIV).

\section{Mice}

Male R6/1 transgenic mouse (B6CBA background) expressing the $\mathrm{N}$-terminal exon 1 fragment of mutant $H T T$ with 115 CAG repeats (obtained originally from The Jackson Laboratory) and their wt littermate controls were used for this study. Genotyping was performed by PCR from tail biopsy samples using primers designed for the expansion of the exon 1 of the mutant $H T T$ as previously described (Mangiarini et al., 1996). All mice were housed together in numerical birth order in groups of mixed genotypes with access to food and water ad libitum in a colony room kept at $19-22^{\circ} \mathrm{C}$ and $40-60 \%$ humidity, under a 12/ $12 \mathrm{~h}$ light/dark cycle. Mice were exsanguinated at 8,12 , 20 , and 30 weeks of age and brain was quickly removed for cortex, hippocampi and striata dissection. All procedures were conducted in accordance with the National Institutes of Health Guide for the Care and Use of Laboratory Animals, and approved by the local animal care committee of the Universitat de Barcelona, following European (2010/63/UE) and Spanish (RD53/2013) regulations for the care and use of laboratory animals.

\section{Postmortem human brain tissue}

Frozen samples of hippocampus and cerebral cortex from HD patients and control individuals were obtained from the Neurologic Tissue Bank of the Biobank-Hospital Clínic-Institut d'Investigacions Biomèdiques August Pi i Sunyer (IDIBAPS) following the guidelines and approval of the local ethics committee (Hospital Clínic of Barcelona's Clinical Research Ethics Committee). Informed consent was obtained from all subjects, and experiments were performed following the guidelines and approval of the local ethics committee. Details on the sex, age, CAG repeat length, Vonsattel grade, and postmortem delay are found in Table 1.

\section{Immunocytochemistry}

Hdh cells grown on poly-L-lysine-coated coverslips were fixed and treated as previously described (Kannike et al., 2014). Rabbit polyclonal anti-TCF4 (\#HLH201, CeMines) and other polyclonal antibodies (Extended Data Fig. 1-1, CeMines) were diluted 1:200 and Alexa Fluor 488-conjugated goat anti-rabbit IgG antibodies (Invitrogen) were diluted 1:2000 in 0.2\% BSA and 0.1\% Tween 20 in PBS. DNA was counterstained with DAPI included in the mounting medium (ProLong Gold Antifade mountant with DAPI; Thermo Fisher). The specificity of the nuclear signal of the used TCF4 antibody has been validated previously (Sepp et al., 2017).

\section{Western blotting}

Hdh cells and rat cultured cortical neurons were lysed in RIPA buffer (50 mm Tris-HCl, pH 8, $150 \mathrm{~mm} \mathrm{NaCl}, 1 \%$ NP-40, $0.5 \%$ sodium deoxycholate, $0.1 \%$ SDS, $1 \mathrm{~mm}$ dithiothreitol and protease inhibitors cocktail Complete mini; Roche). Cell lysates were sonicated for $15 \mathrm{~s}$ with $30 \%$ amplitude on Sonics VibraCell and centrifuged at $16,100 \times g$ for $15 \mathrm{~min}$ at $4^{\circ} \mathrm{C}$. Nuclear and cytosolic fractions of Hdh cells were prepared with NE-PER Nuclear and Cytoplasmic Extraction kit (Thermo Scientific) according to the manufacturer's instructions. Protein concentrations in lysates were measured with BCA Protein Assay kit (Pierce).

Protein extraction from mouse brain and human postmortem samples from the cerebral cortex and CA1 region of the hippocampus was performed using a lysis buffer containing $50 \mathrm{~mm}$ TRIS (pH 7.4), 10\% glycerol, $1 \%$ Triton $\mathrm{X}-100,150 \mathrm{~mm} \mathrm{NaCl}, 5 \mu \mathrm{M} \mathrm{ZnCl}_{2}, 10 \mathrm{~mm}$ EGTA and protease inhibitors [2 mM phenylmethylsulfonyl fluoride (PMSF), $10 \mu \mathrm{g} / \mu \mathrm{l}$ aprotinin, and $1 \mu \mathrm{g} / \mu \mathrm{l}$ leupeptin] and phosphatase inhibitors (2 $\mathrm{mm} \mathrm{Na}_{3} \mathrm{VO}_{4}$ and $100 \mathrm{~mm} \mathrm{NaF}$ ). Samples were homogenized and supernatants were collected after centrifugation at $15,000 \times g$ for $15 \mathrm{~min}$ at $4^{\circ} \mathrm{C}$. Protein concentration was measured using Dc protein assay kit (Bio-Rad Laboratories).

TCF4 isoforms $\mathrm{A}^{-}, \mathrm{B}^{-}, \mathrm{C}^{-}$and $\mathrm{D}^{-}$were in vitro translated using TnT Quick Coupled Transcription/Translation System (Promega) according to the manufacturer's instructions. The used DNA constructs have been described previously (Sepp et al., 2011). The frontal cortex lysates from E18 Tcf4 knock-out (KO) and wt mice were a kind gift from 
Table 1: Hippocampus CA1 and cerebral cortex tissue samples of HD patients

\begin{tabular}{|c|c|c|c|c|c|c|}
\hline ID & Region & Pathologic diagnosis & Gender & Age (years) & CAG repeats & PMD (h:min) ${ }^{\star}$ \\
\hline$\overline{\mathrm{CS}-497}$ & $\overline{\mathrm{CA} 1}$ & Control & $\bar{M}$ & 82 & & $02: 30$ \\
\hline CS-1858 & CA1 & Control & $\mathrm{F}$ & 83 & & $07: 30$ \\
\hline CS-1888 & CA1 & Control & $\mathrm{F}$ & 93 & & $05: 30$ \\
\hline CS-1937 & CA1 & Control & $\mathrm{F}$ & 83 & & $07: 33$ \\
\hline CS-1949 & CA1 & Control & M & 86 & & $07: 25$ \\
\hline CS-1334 & CA1 & HD, Vonsattel grade 1 & M & 73 & $40 \pm 2$ & 07:00 \\
\hline CS-1438 & CA1 & HD, Vonsattel grade 3 & M & 85 & 40 & $05: 30$ \\
\hline CS-1630 & CA1 & HD, Vonsattel grade 2 & $\mathrm{M}$ & 76 & 41 & 06:00 \\
\hline CS-1638 & CA1 & HD, Vonsattel grade 2 & M & 72 & - & $13: 10$ \\
\hline CS-1844 & CA1 & HD, Vonsattel grade 2 & $\mathrm{~F}$ & 69 & 43 & $15: 30$ \\
\hline CS-1874 & CA1 & HD, Vonsattel grade 3 & $M$ & 56 & 43 & $04: 30$ \\
\hline 1697 & Cortex & Control & $M$ & 78 & & $06: 00$ \\
\hline 1870 & Cortex & Control & $\mathrm{F}$ & 97 & & $07: 20$ \\
\hline 1937 & Cortex & Control & $\mathrm{F}$ & 83 & & $07: 33$ \\
\hline 1949 & Cortex & Control & $M$ & 86 & & $07: 25$ \\
\hline 1980 & Cortex & HD, Vonsattel grade 3 & $\mathrm{~F}$ & 69 & - & $12: 30$ \\
\hline 1875 & Cortex & HD, Vonsattel grades $2-3$ & $\mathrm{M}$ & 84 & 39 & 08:00 \\
\hline 1844 & Cortex & HD, Vonsattel grade 2 & $\mathrm{~F}$ & 69 & 43 & $15: 30$ \\
\hline 1638 & Cortex & HD, Vonsattel grade 2 & $M$ & 72 & - & $13: 10$ \\
\hline 1630 & Cortex & HD, Vonsattel grade 2 & M & 76 & 38 & 06:00 \\
\hline 909 & Cortex & HD, Vonsattel grade 4 & M & 60 & 43 & $13: 30$ \\
\hline
\end{tabular}

Details of human postmortem samples used for Western blotting to analyze protein levels of TCF4. All samples received from the Neurologic Tissue BankBiobanc located at the University of Barcelona School of Medicine. *PMD, postmortem delay.

Brady Maher and have been described in more detail previously (Li et al., 2019).

Equal amounts of protein were separated in $8 \%$ gel in SDS-PAGE followed by wet transfer to Hybond-C nitrocellulose membrane (GE Healthcare) or to PVDF membrane (Merck Millipore). Membranes were blocked $1 \mathrm{~h}$ at room temperature (RT) in PBS containing 5\% skimmed milk and $0.1 \%$ Tween 20 , incubated overnight at $4^{\circ} \mathrm{C}$ with primary antibodies and $1 \mathrm{~h}$ at RT with secondary antibodies in $0.1 \%$ Tween 20 (and 5\% BSA for the mouse and postmortem human brain samples) and $2 \%$ skimmed milk in PBS. Antibodies were diluted as follows: 1:200 rabbit polyclonal anti-TCF4 (TCF4_02; $200 \mathrm{ng} / \mathrm{ml}$; Forrest et al., 2018), 1:1000 mouse monoclonal anti-TCF4 (ITF-2 C-8; \#sc-393407; 200 g/ml; Santa Cruz), rabbit polyclonal anti-HDAC2 1:1000 (\#sc-7899, Santa Cruz), mouse monoclonal anti- $\beta$ tubulin to final concentration $30 \mathrm{ng} / \mathrm{ml}$ (E-7, DSHB), anti- $\alpha$ tubulin (T9026, SigmaAldrich) and HRP-conjugated goat anti mouse or rabbit IgG $(\mathrm{H}+\mathrm{L})$ 1:2500 (\#32430 and \#32460, respectively; Thermo Scientific). Chemoluminescence signal was detected using SuperSignal West Femto Chemoluminescent Substrate (Thermo Scientific) and ImageQuant 400 imaging system (GE Healthcare). Additionally, Coomassie staining was used to quantify loading in five independent Western blotting experiments with Hdh total lysates. Briefly, the membrane was stained with Coomassie solution $(0.1 \%$ Coomassie Brilliant Blue R-250 dye, 25\% ethanol, 7\% acetic acid), followed by two washes with destaining solution
(30\% ethanol, 10\% acetic acid) and rinsing with tap water. Densitometric quantification was done using ImageQuant T4 v2005 software (GE Healthcare) or Gel-Pro Analyzer version 4 (Media Cybernetics).

\section{TCF4 transcripts data mining and visualization}

Mouse Tcf4 gene structure and mRNAs were identified by analyzing genomic, mRNA and expressed sequence tag (EST) databases available at https:// genome.ucsc.edu/ and https://www.ncbi.nlm.nih.gov/ nuccore. Accession numbers of representative mouse mRNA or EST sequences for alternative Tcf4 transcripts are shown in Table 2, based on Mouse Dec. 2011 GRCm38/mm10 genome assembly. Human transcript data adapted from Sepp et al. (2011) is included for reference (Human Dec. 2013, GRCh38/hg38 assembly).

\section{RNA extraction and cDNA synthesis}

Total RNA from Hdh cells and cultured cortical neurons was extracted using RNeasy Micro kit (QIAGEN) following the manufacturer's instructions. R6/1 mouse brain tissue was homogenized in QIAZol reagent (QIAGEN) and total RNA was extracted with RNeasy Lipid Tissue Mini kit (QIAGEN) according to the manufacturer's protocol including on-column DNase I treatment. First-strand cDNAs were synthesized from 1 to $5 \mu \mathrm{g}$ of total RNA with Superscript III First-Strand synthesis system (Invitrogen) together with oligo(dT) $)_{20}$ or a combination of oligo $(\mathrm{dT})_{20}$ 
Table 2: Accession numbers of representative mRNA or EST sequences for alternative Tcf4 transcripts and protein isoforms they encode in mouse and human

\begin{tabular}{|c|c|c|c|}
\hline \multicolumn{4}{|c|}{ Alternative TCF4 transcripts and isoforms } \\
\hline Transcript & $\begin{array}{l}\text { Protein } \\
\text { isoform }\end{array}$ & Mouse & Human \\
\hline $3 \mathrm{~b}$ & $\mathrm{~B}$ & AK133885 & AK315074 \\
\hline $3 b \Delta 3$ & $\mathrm{C}$ & $\overline{\mathrm{AK051958}}$ & $\overline{\text { AK299169 }}$ \\
\hline $3 c$ & $\mathrm{~B}$ & $\overline{\mathrm{AK} 081012}$ & $\overline{\mathrm{DB} 106801}$ \\
\hline $3 c \Delta 3$ & $\mathrm{E}$ & ENSMUST00000202354.3 & $\overline{F R 748216}$ \\
\hline $3 c \Delta 8-9$ & $\mathrm{~B} \Delta$ & $\overline{\text { ENSMUST00000202772.3 }}$ & $\overline{\text { FR748212 }}$ \\
\hline $3 d$ & B & CJ182557 & $\overline{\mathrm{M} 74719}$ \\
\hline $4 c$ & $\mathrm{C}$ & CJ115804 & DC358747 \\
\hline $7 a-11$ & $\mathrm{D}$ & $\overline{\text { BY247629 }}$ & $\overline{\mathrm{AK} 300612}$ \\
\hline $7 b-1$ & $\mathrm{D} / \mathrm{G}$ & $\overline{\text { XM_017317861 }}$ & $\overline{\mathrm{AK} 095041}$ \\
\hline $7 b-11$ & $\mathrm{D}$ & $\overline{\text { CD350230 }}$ & $\overline{\mathrm{DC} 350124}$ \\
\hline $8 a$ & $\mathrm{D}$ & $\overline{\text { BY286412 }}$ & AK316165 \\
\hline $8 b * / 8 b-1$ & $\mathrm{D}$ & $\overline{\mathrm{CB} 178848}$ & $\overline{\text { FR748208 }}$ \\
\hline 8b-II & D & $\overline{\mathrm{BY} 252182}$ & AK300636 \\
\hline $8 c-11$ & $\mathrm{D}$ & $\overline{\mathrm{BB} 663894}$ & $\overline{\mathrm{CA} 393351}$ \\
\hline $8 e / 8 d$ & $\mathrm{D}$ & $\overline{\text { BY259217 }}$ & $\overline{\text { BP230382 }}$ \\
\hline $10 a$ & A & U16321 & $\overline{\mathrm{AK} 300038}$ \\
\hline $10 b$ & I & $\overline{B U 058820}$ & $\overline{\mathrm{BP} 241032}$ \\
\hline $10 c$ & $\mathrm{H}$ & BY333068 & DA664480 \\
\hline
\end{tabular}

Reference for transcripts of human TCF4 were obtained from Sepp et al. (2011). Data are according to Mouse Dec. 2011 (GRCm38/mm10) Assembly and Human Dec. 2013, GRCh38/hg38 assembly. ${ }^{*}$ TSS differs between human and mouse. The respective human transcript is shown after slash.

and random hexamer primers (Microsynth) in case of cultured cells and R6/1 brain RNA, respectively.

\section{Quantitative PCR (qPCR)}

qPCRs were performed in triplicates using LightCycler 480 SYBR Green I Master (Roche) with cDNA from Hdh cells and 3-NP-treated cultured cortical neurons and $5 \times$ HOT FIREPol EvaGreen qPCR Mix Plus (Solis Biodyne) with R6/1 mouse brain cDNAs on LightCycler 480 II Real Time PCR System (Roche). Levels of Sdha or Hprt1 (for HD cell model experiments: Hdh and 3-NP-treated neurons, respectively) or geometric mean of Hprt1, Gapdh, and Tbp (for R6/1 mouse experiments) mRNA levels were used to normalize qPCR data. Primer pairs used in qPCR are shown in Table 3.

\section{Plasmid constructs}

Expression constructs pcDNA.3.1/EF1a/TCF4-B ${ }^{-}$and pcDNA.3.1/EF1a/TCF4- $A^{-}$have been characterized previously (Sepp et al., 2017). The constructs for TCF4-C ${ }^{-}$, TCF4-D', and TCF4-I' were created similarly from the respective pcDNA3.1 constructs as described (Sepp et al., 2011) by replacing the cytomegalovirus $(C M V)$ promoter with elongation factor $1(E F 1 \alpha)$ promoter from pGL4.83[hRlucP/EF1 $\alpha /$ Puro]. pcDNA3.1/PGK/ASCL1 was cloned from pcDNA3.1/SR $\alpha /$ ASCL1 (Sepp et al., 2017) replacing $S R \alpha$ promoter with $P G K$ promoter from pGL4.83 [hRlucP/PGK1/Puro]. Luciferase reporter system constructs pGL4.29[luc2P/12 $\mu \mathrm{E} 5 / \mathrm{TK} / \mathrm{Hygro}$ ] with $12 \mathrm{E}$-boxes in front of thymidine kinase promoter, and pGL4.83[hRlucP/PGK1/ Puro] with phosphoglycerate kinase 1 promoter have been characterized previously (Sepp et al., 2011, 2017).

\section{Luciferase reporter assay}

Neurons plated on 48-well plates were transfected at 6 DIV using Lipofectamine 2000 (Invitrogen) with a reagent to DNA ratio $3: 1$. For luciferase reporter assays, $0.06 \mu \mathrm{g}$ of TCF4 isoforms $\mathrm{B}^{-}, \mathrm{C}^{-}, \mathrm{D}^{-}, \mathrm{A}^{-}$, and $\mathrm{I}^{-}$, and $0.06 \mu \mathrm{g}$ of ASCL1 encoding constructs were used, $0.06 \mu \mathrm{g}$ of firefly luciferase construct pGL4.29[luc2P/12 $\mu \mathrm{E} 5 / \mathrm{TK} / \mathrm{Hyg}$ ro], and $0.02 \mu \mathrm{g}$ of Renilla luciferase pGL4.83[hRlucP/PGK1/ Puro] were used. At 7 DIV, the neuronal cultures were left untreated or treated with $25 \mathrm{~mm} \mathrm{KCl}$ for $8 \mathrm{~h}$. Cells were lysed in Passive Lysis buffer (Promega) and Dual-Glo Luciferase assay (Promega) was used for measuring luciferase signals. Luciferase assay was performed in technical duplicates and in total three independent experiments were conducted both on cortical and hippocampal primary neurons. Normalized luciferase data were used to calculated co-operation indices between TCF4 and ASCL1 as described (Chang et al., 1996). Briefly, co-operation index shows how many times the transactivation fold is increased in neurons co-expressing different TCF4 isoforms and ASCL1 compared with the sum of transactivation folds from neurons expressing both proteins separately.

\section{Statistical analysis}

For quantification of Western blotting data TCF4 signals were normalized to the signals of $\beta$ tubulin ( $\mathrm{Hdh}$ whole

Table 3: List of oligonucleotides used in this study

\begin{tabular}{|c|c|c|}
\hline Gene (transcript) & Forward primer sequence & Reverse primer sequence \\
\hline Tcf4-A & caCCATGTACTGCGCATACACCATC & TGGATGCAGGCTACAGTAGCTG \\
\hline$T c f 4-D(8 c-I I)$ & CAGCTGAAATGATTCCCCACTGTG & TGGATGCAGGCTACAGTAGCTG \\
\hline$T c f 4-D(7 b-I)$ & GTCTTGCTTGCATACATTGCCAG & GTTTGGTGGGCGAAAGGGTTCC \\
\hline Tcf4-I & GAGAAAGCCCAAGTTAGGCTGAG & TGGATGCAGGCTACAGTAGCTG \\
\hline Neurod1 & ACACGAGGCAGACAAGAAgG & TCTTGGGCTTTTGATCaTCC \\
\hline Hprt1 & CAGTCCCAGCGTCGTGATTA & AGCAAGTCTTTCAGTCCTGTC \\
\hline Sdha & AACACTGGAGGAAGCACAC & GGAACGGATAGCAGGAGGT \\
\hline Gapdh & TGCACCACCAACTGCTTAGC & GGCATGGACTGTGGTCATGAG \\
\hline Tbp & TGCACAGGAGCCAAGAGTGAA & CACATCACAGCTCCCCACCA \\
\hline
\end{tabular}


and cytoplasmic lysates; Fig. 2C,E), HDAC2 (nuclear lysates; Fig. 2E), Coomassie staining (Hdh whole lysates; Fig. $2 C$ ), or $\alpha$ tubulin (lysates from human CA1 region of the hippocampus and cerebral cortex; Fig. $4 F, H)$. The data were log-transformed to ensure normal distribution, autoscaled (where indicated in the figure legend), mean and SEM were calculated, and two-tailed $t$ tests were used for statistical analysis (Extended Data Figs. 2-1, 4-1). The data were backtransformed into the linear scale for graphical representation, error bars represent upper and lower limits of the back-transformed mean \pm SEM. For analysis of TCF4 protein levels in R6/1 mouse brain time series, the TCF4 signals were normalized to the signals of $\alpha$ tubulin, data were log-transformed, mean and mean \pm SEM were calculated for each group, and the average expression level of the respective transcript in each age group was set as 0 ( 1 in linear scale). Generalized linear model with Gaussian distribution using the formula genotype + age:genotype was used, followed by Wald $\chi^{2}$ test (Type III test, performed with Car package in R; Fox and Weisberg, 2019) to determine $p$ values of the coefficients. For graphical representation, data were back-transformed to the linear scale, with error bars showing back-transformed mean \pm SEM. qPCR data generated from Hdh cell line and 3-NPtreated rat primary cortical neurons were log-transformed and autoscaled, mean and \pm SEM values were calculated, and two-tailed paired $t$ tests were performed (Extended Data Fig. 2-1). For graphical representation the data were backtransformed into the linear scale, error bars represent upper and lower limits of the back-transformed mean \pm SEM. For analysis of transcript levels in time series of R6/1 mouse brain, data were log-transformed, mean and mean \pm SEM were calculated for each group, and the average expression level of the respective transcript in eight-week-old wt animals was set as 0 ( 1 in linear scale). Generalized linear model with Gaussian distribution using the formula age + genotype + age:genotype was used, followed by Wald $\chi^{2}$ test (Type III test, performed with Car package in R; Fox and Weisberg, 2019) to determine $p$ values of the coefficients. For graphical representation, data were back-transformed to the linear scale, with error bars showing back-transformed mean \pm SEM.

For luciferase reporter assay, Firefly luciferase signals were normalized to the Renilla luciferase signal, data were then subjected to log transformation, mean centering, and autoscaling to obtain normal distribution. For graphical representation, the data were back-transformed to the original scale. One-way repeated-measures ANOVA with Greenhouse-Geisser correction followed by Tukey's post hoc test was used to determine statistical significance compared with the full-length TCF4-B ${ }^{-}$in different conditions using Prism 7 software (GraphPad; Extended Data Fig. 6-1).

Numbers of independent experiments and biological samples are indicated in figure legends; R6/1 mouse samples are summarized in Table 4.

\section{Results}

\section{Identification of TCF4 as a misregulated transcription factor in HD}

Mislocalized nucleoporins and impaired nucleocytoplasmic transport have been described in several HD models and patients (Grima et al., 2017). We used a panel of $>200$ antibodies (Extended Data Fig. 1-1) generated against various transcription and transcription associated factors to screen for differential immunocytochemical signals in mouse striatal progenitor cell lines $\mathrm{Hdh}^{7 / 7}$ (wt), $\mathrm{Hdh}^{7 / 109}$ (heterozygous for HD mutation), and $\mathrm{Hdh}^{109 / 109}$ (homozygous for HD mutation). Our screen revealed 8 antibodies that showed differential signals in wt and mutant Hdh cells (Fig. 1A; Extended Data Fig. 1-2), including the $\mathrm{FOXO} 3$ antibodies that display increased nuclear signals in the mutant cells as reported earlier (Kannike et al., 2014). It must be noted, however, that most of the used antibodies have not been validated for immunocytochemical detection of endogenous proteins, and thus the results of the screen should be interpreted with caution. Antibodies generated against the basic helix-loop-helix (bHLH) transcription factor TCF4 showed reduced nuclear signals in Hdh cell lines expressing expanded $H$ tt alleles (Fig. 1A). The specificity of the nuclear signal of these TCF4 antibodies has been demonstrated, whereas the cytoplasmic signal has been shown to be unspecific (Sepp et al., 2017). Therefore, our results suggest a difference in TCF4 localization and/or expression in $\mathrm{Hdh}^{7 / 7}, \mathrm{Hdh}^{7 / 109}$, and $\mathrm{Hdh}^{109 / 109}$ cells. Considering that TCF4 is an essential transcription factor in brain development and is linked to intellectual disability (Zweier et al., 2007; Kalscheuer et al., 2008; Blake et al., 2010), we sought to further characterize the potential misregulation of TCF4 in HD.

Human TCF4 is a complex gene with 41 exons, out of which 21 are alternative $5^{\prime}$ exons. Human TCF4 protein isoforms with 18 different $\mathrm{N}$ termini and additional variance resulting from alternative splicing at the cassette exons 8-9 (full-length and $\delta$ isoforms) and exon 18 [+/isoforms differing by four amino acids (RSRS)] have been described (Sepp et al., 2011). To elucidate the structure of the mouse Tcf4 gene we gathered data from public databases about mouse Tcf4 expressed sequences (Fig. 1B, $C$; Table 2). The general gene structure of mouse Tcf4 is similar to human TCF4. Compared with the human TCF4 gene, fewer transcripts are reported for mouse Tcf4 and these encode protein isoforms with seven different $\mathrm{N}$ termini (Fig. 1B). There were two rare TCF4-B $\Delta$ and one TCF4-E isoform encoding transcripts present in the databases. Our analysis of mouse Tcf4 data revealed seven alternative TCF4-D-coding transcripts linked to different 5' untranslated exons with translation initiation codon in exon 8 for all of them. Of note, a nucleotide addition in $5^{\prime}$ alternative exon $7 \mathrm{~b}-\mathrm{I}$ prevents the expression of TCF4-G in mice and TCF4-D is coded instead (Fig. 1C). The transcript starting from exon 8d, expressed in human, has not been described in mouse. Instead, transcript $8 \mathrm{e}$ (with a different transcription start site) is expressed in mouse.

Collectively, we have determined that the TCF4 gene structure is highly conserved between mouse and human and our results suggest misregulation of TCF4 in the mutant $\mathrm{HTT}$-expressing mouse striatal cells.

\section{TCF4 levels are reduced in cell-based HD models}

To dissect the contribution of different TCF4 isoforms to the altered immunocytochemical signal of TCF4 
A

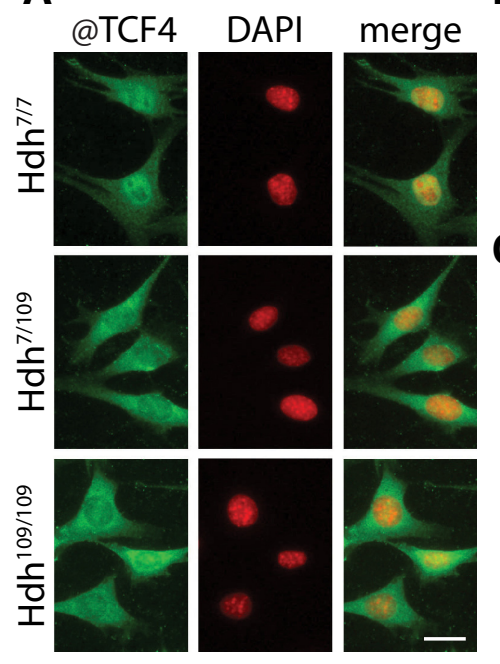

B

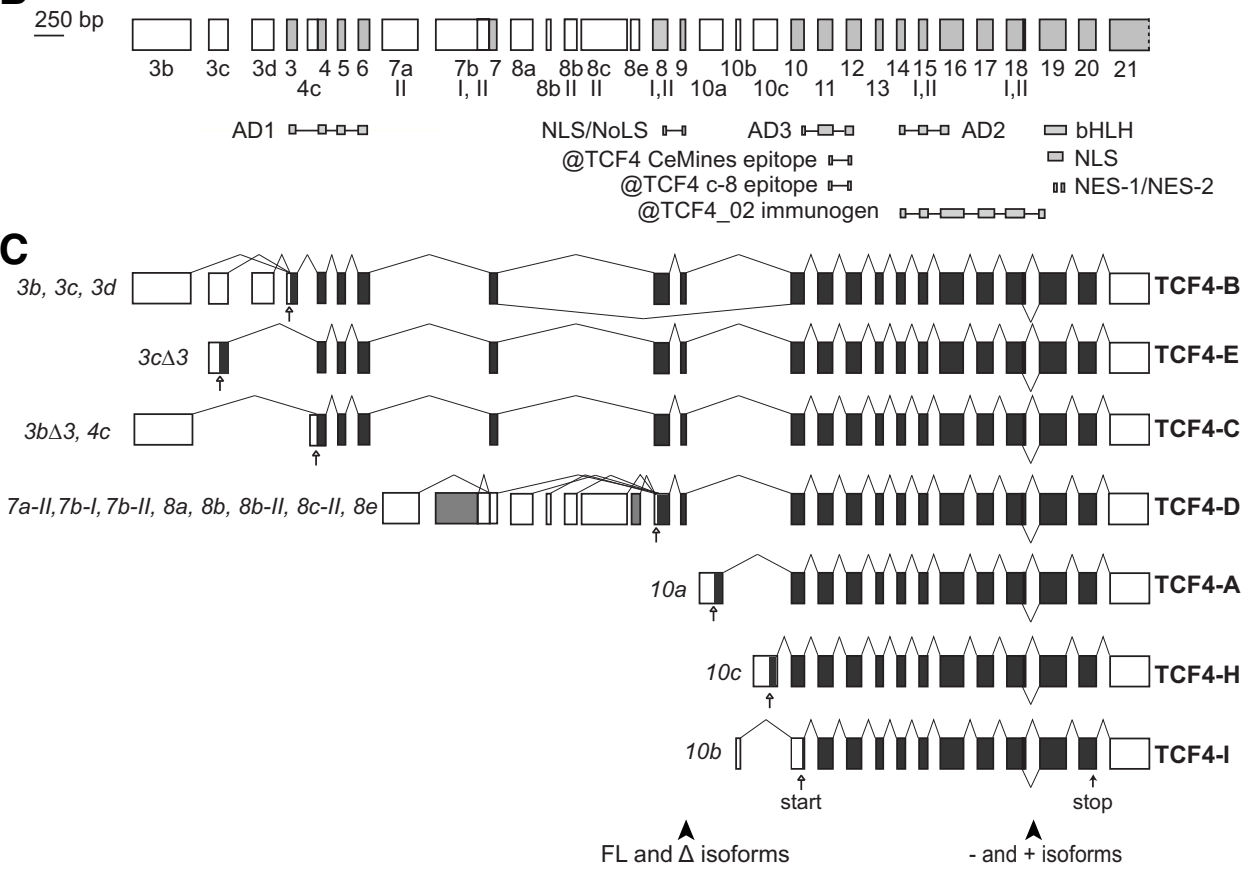

Figure 1. Differential immunocytochemical signal of endogenous TCF4 in Hdh cells and the structure and alternative splicing of mouse Tcf4 gene. A, Representative micrographs showing distribution of immunocytochemical signal obtained with anti-TCF4 antibodies (\#HLH210, CeMines) in $\mathrm{Hdh}^{7 / 7}, \mathrm{Hdh}^{7 / 109}$, and $\mathrm{Hdh}^{109 / 109}$ cells. Antibodies used for the immunocytochemical screen in Hdh cells are listed in Extended Data Figure 1-1. Results of the screen with additional antibodies (CeMines) that showed differential signals in wt and mutant Hdh cells are shown in Extended Data Figure 1-2. DNA was counterstained with DAPI. Scale bar: $20 \mu \mathrm{m}$. B, Mouse Tcf4 genomic organization with exons drawn in scale. Gene structure layout and exon numbering is based on Sepp et al. (2011) for convenient comparison with human TCF4 gene. 5' exons are marked with white boxes and internal or 3' exons are shaded in light gray. Exon names are displayed below boxes. Roman numerals designate alternative splice donor or acceptor sites, with some missing compared with the human TCF4. The regions encoding the respective domains of TCF4 and the epitopes of the used TCF4 antibodies [polyclonal @TCF4 (\#HLH20, CeMines), polyclonal @TCF4_02 (Forrest et al., 2018), and monoclonal @TCF4 (Santa Cruz c-8)] are indicated below the gene structure. AD, activation domain; bHLH, basic helix-loop-helix; NLS, nuclear localization signal; NES, nuclear export signal; NoLS, nucleolar localization signal. $\boldsymbol{C}$, Alternative transcripts of mouse Tcf4 grouped together according to the encoded TCF4 protein isoform. Translated and untranslated regions are designated as dark gray and white boxes, respectively. Transcripts are designated with the name of the $5^{\prime}$ exon and, where necessary, with the number of the splice site used in the $5^{\prime}$ exon. Accession numbers of the representative mouse Tcf4 transcripts presented here are listed in Table 2. Transcripts using the $5^{\prime}$ exon $7 \mathrm{~b}-\mathrm{I}$ (shown with gray) is translated into TCF4-D in mouse and TCF4-G in human and transcript 8e (shown with gray) is unique to mouse. The name of the protein isoform is shown on the right. The position of the first in-frame start codon for each transcript and stop codon are shown with empty and filled arrows, respectively. Arrowheads at the bottom of the panel point to the regions of alternative splicing giving rise to $\Delta$ isoform or + and - isoforms.

detected in HD cells, we next studied TCF4 protein levels in Hdh cell lines by Western blotting. First, we used cortical lysates from Tcf4 KO mice (Li et al., 2019) to validate the specificity of two TCF4 antibodies, polyclonal antibody anti-TCF4_02 (Forrest et al., 2018) and a commercial monoclonal antibody anti-TCF4 C-8 (Santa Cruz; Fig. $2 A, B)$ and determined the mobility pattern of different TCF4 isoforms overexpressed in HEK293 cell lysates (data not shown). We then analyzed total cell lysates of Hdh cells by Western blotting with polyclonal antiTCF4_02 antibody ( $n=3$; Fig. 2C) and anti-TCF4 c-8 antibody $(n=5)$. Based on the predicted molecular weight $(\mathrm{Mw})$ and mobility of in vitro translated isoforms TCF4-Band TCF4-A ${ }^{-}$, we divided the detected TCF4 protein bands into two groups: high $\mathrm{Mw}$ isoforms, similar to isoforms TCF4-B and TCF4-C and their respective +/- isoforms, and medium/low $\mathrm{Mw}$ isoforms, which probably correspond to TCF4-D, TCF4-A, TCF4-H, and TCF4-I and their respective $+/-$ isoforms. Of note, + isoforms have higher mobility than isoforms in SDS-PAGE gels as described previously (Sepp et al., 2011). We observed a significant $>30 \%$ decrease of both high and low Mw TCF4 isoforms in both mutant $\mathrm{Hdh}$ cell lines compared with wt Hdh cells (Fig. 2C,D).

Next, to further decipher the changes in TCF4 levels we fractionated Hdh cells into cytoplasmic and nuclear lysates and analyzed the lysates by Western blotting with polyclonal TCF4_02 antibody ( $n=3$; Fig. $2 E)$. In vitro translated isoforms TCF4-B ${ }^{-}$, TCF4-A-, TCF4-C ${ }^{-}$, and TCF4-D' were used to decipher bands detected in Hdh cell lysates. TCF4 protein levels were reduced in both cytoplasmic and nuclear fractions of mutant Hdh cells (Fig. 2F). In mutant Hdh cell cytoplasm the levels of TCF4 were downregulated to $\sim 40 \%$ of TCF4 detected in wt cells, with statistical significance only for $\mathrm{Hdh}^{109 / 109}$ (Fig. 2F). In the nuclear fraction, a visible reduction was observed in both 
A

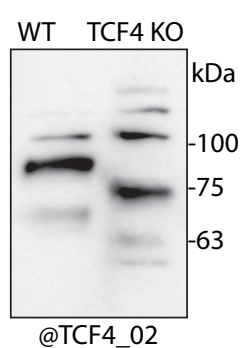

B

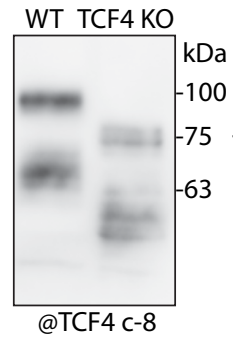

C

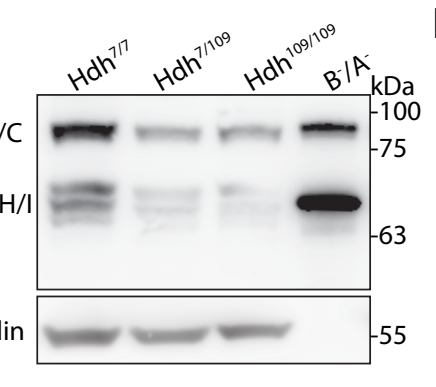

D

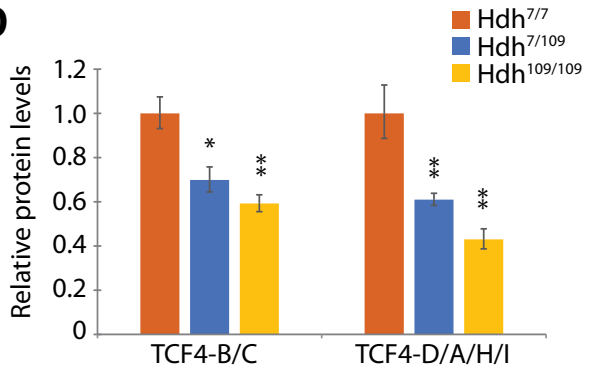

E Cytoplasm Nucleus

$\mathbf{F}$ F Cytoplasm

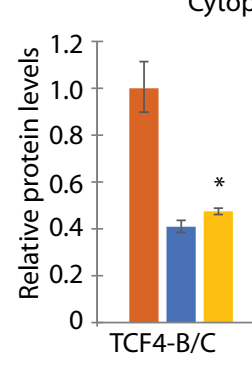

Nucleus

$\mathrm{Hdh}^{7 / 7}$

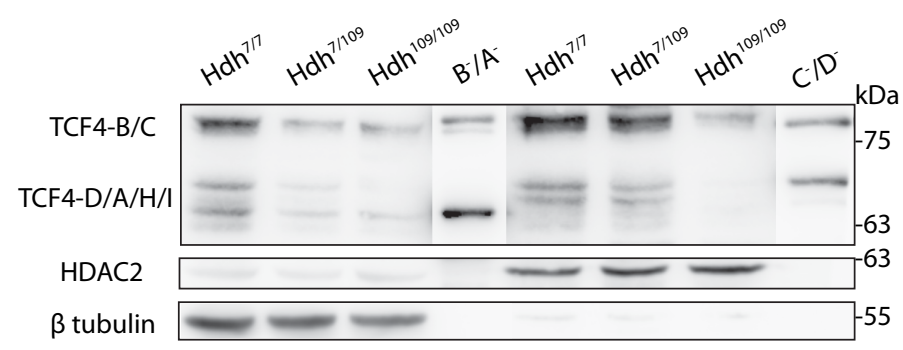

H

G H $\begin{aligned} & \text { untreated } \\ & \text { 3-NP } 8 \mathrm{~h}\end{aligned}$
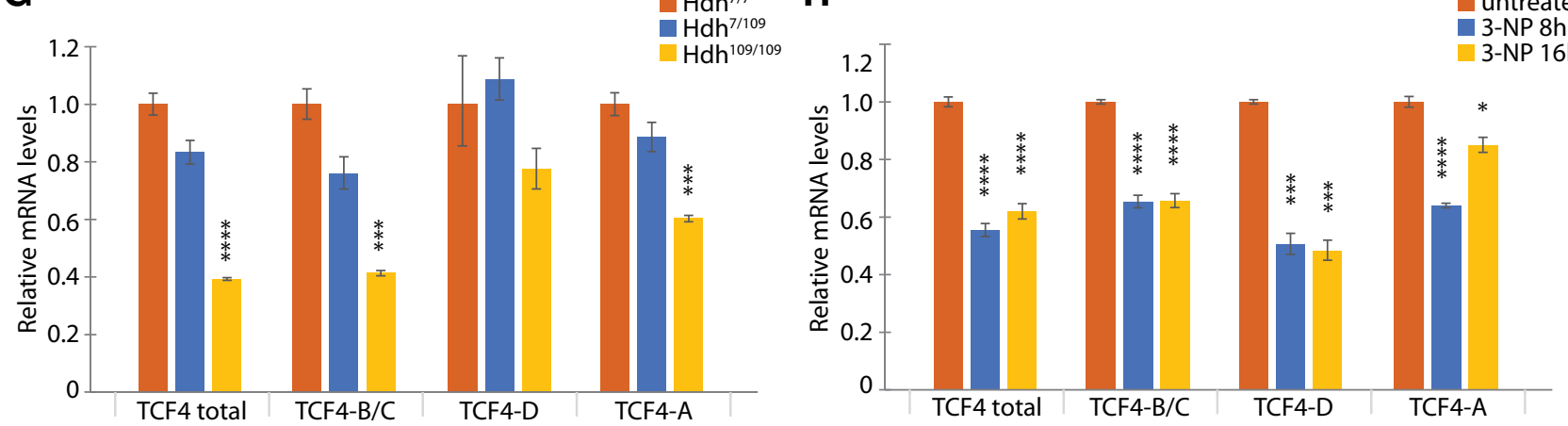

Figure 2. Protein and mRNA levels of transcription factor TCF4 in HD cell models. $\boldsymbol{A}, \boldsymbol{B}$, Validation of TCF4_02 polyclonal (A) and TCF4 c-8 monoclonal antibodies (B). Western blot analysis of E18 wt and Tcf4 KO mice brain total lysates (Li et al., 2019). The KO mice express truncated TCF4 proteins that lack $C$ terminus of the wt protein, but maintain the regions targeted by the used antibodies. $\boldsymbol{C}, \boldsymbol{E}$, Representative Western blot analysis of TCF4 protein levels in total lysates $(\boldsymbol{C})$ and cytoplasmic and nuclear fractions $(\boldsymbol{E}$; 100 and $50 \mu \mathrm{g}$ of protein, respectively) of wt $\mathrm{Hdh}^{7 / 7}$, heterozygous mutant $\mathrm{Hdh}^{7 / 109}$ and homozygous mutant $\mathrm{Hdh}^{109 / 109} \mathrm{cells}^{\text {In }}$ vitro translated human TCF4- $\mathrm{A}^{-}$, TCF4-B ${ }^{-}$, TCF4- $\mathrm{C}^{-}$, and TCF4-D ${ }^{-}$were added as controls. $\beta$ tubulin served as a loading control for total and cytoplasmic lysates and HDAC2 for nuclear lysates. $\boldsymbol{D}, \boldsymbol{F}$, Quantification of data in $\boldsymbol{C}$ ( $n=8$ independent experiments) and in $\boldsymbol{E}$ $(n=3)$, respectively. TCF4-B and TCF4-C were quantified together as high Mw isoforms (TCF4-B/C), and TCF4-D, TCF4-A ${ }^{+}$, and TCF4- $\mathrm{A}^{-}$together as low Mw isoforms (TCF4-D/A $/ \mathrm{A}^{+}$). In $\boldsymbol{D}$, TCF4 signals were normalized to either the levels of $\beta$ tubulin (for three experiments) or Coomassie Blue staining (for five experiments). In $\boldsymbol{F}$, signal intensities were normalized to $\beta$ tubulin signal intensities in the cytosolic fraction and to HDAC2 in nuclear fraction. The relative TCF4 levels in Hdh ${ }^{7 / 7}$ were arbitrarily set as 1 . The data were log-transformed, autoscaled, means and SEMs were calculated, and statistical significance is shown relative to the levels of respective TCF4 isoforms measured in $\mathrm{Hdh}^{7 / 7}$ cells; ${ }^{*} p<0.05,{ }^{* *} p<0.01$, paired Student's $t$ test. Precise $p$ values are reported in Extended Data Figure 2-1. The data were back-transformed into the linear scale for graphical representation, error bars represent upper and lower limits of back-transformed mean \pm SEM. G, $\boldsymbol{H}, \mathrm{RT}$-qPCR analysis of total Tcf4 mRNA, transcripts encoding long (TCF4-B and TCF4-C), medium (TCF4-D), and short (TCF4-A) isoforms in mouse Hdh cells $(\mathbf{G} ; n=3)$ and in rat primary cortical neurons untreated or treated with 3-NP for 8 or $16 \mathrm{~h}(\boldsymbol{H} ; n=5)$. Tcf4 mRNA levels were normalized to the levels of Sdha or Hprt1 mRNA, respectively. The data were log-transformed, autoscaled, and the mean values and mean \pm SEM were calculated. Statistical significance is shown relative to the expression level of the respective Tcf4 transcripts in $\mathrm{Hdh}^{7 / 7}$ cells or untreated neurons. The data were back-transformed into linear scale for graphical depiction and error bars represent upper and lower limits of back-transformed mean $\pm \mathrm{SEM}$; ${ }^{*} p<0.05,{ }^{\star \star \star} p<0.005,{ }^{* \star \star \star} p<0.001$, paired Student's $t$ test (precise $p$ values are reported in Extended Data Figure 2-1).

mutant cell lines with all TCF4 isoforms, albeit statistical significance was reached only for TCF4 D/A/H/I where protein levels in $\mathrm{Hdh}^{109 / 109}$ cells were reduced to $10 \%$ of the levels of these isoforms in wt cells (Fig. $2 F$ ). Taken together, TCF4 protein levels were reduced in both fractions and especially dramatically in $\mathrm{Hdh}^{109 / 109}$ nuclear fraction. Interestingly, distinct set of medium/low Mw TCF4 isoforms were present in the nucleus compared 
Table 4: R6/1 mouse samples used for quantification of TCF4 mRNA and protein levels

\begin{tabular}{|c|c|c|c|c|c|c|c|c|}
\hline \multirow[b]{2}{*}{ Age } & \multirow[b]{2}{*}{ Genotype } & \multicolumn{4}{|c|}{ RT-qPCR } & \multicolumn{3}{|c|}{ Western blotting } \\
\hline & & CX & STR & HIP & CB & CX & STR & HIP \\
\hline \multirow[t]{2}{*}{8 weeks } & wt & 8 & 8 & 8 & 8 & 6 & 7 & 7 \\
\hline & HD & 7 & 6 & 7 & 7 & 6 & 7 & 7 \\
\hline \multirow[t]{2}{*}{12 weeks } & wt & 8 & 7 & 8 & 6 & 6 & 7 & 6 \\
\hline & $\mathrm{HD}$ & 7 & 7 & 7 & 7 & 7 & 5 & 7 \\
\hline \multirow[t]{2}{*}{20 weeks } & wt & 7 & 7 & 7 & 7 & 7 & 5 & 6 \\
\hline & $\mathrm{HD}$ & 6 & 6 & 5 & 5 & 6 & 6 & 7 \\
\hline \multirow[t]{2}{*}{30 weeks } & wt & 7 & 6 & 6 & 6 & 6 & 4 & 7 \\
\hline & HD & 6 & 6 & 6 & 5 & 6 & 5 & 6 \\
\hline
\end{tabular}

CX, cerebral cortex; STR, striatum; HIP, hippocampus; CB, cerebellum.

with cytoplasm, although the isoform patterning did not differ between Hdh genotypes (Fig. 2F).

To further elucidate changes of TCF4 in HD we sought to study mRNA levels of total Tcf4, combination of the longer transcripts encoding TCF4-B/C and transcripts encoding the most abundant shorter protein isoforms TCF4$\mathrm{D}$ and TCF4-A in mouse Hdh cell lines ( $n=3$; Fig. 2G). Total Tcf4 mRNA levels were pronouncedly downregulated in mutant homozygous Hdh cells - to $40 \%$ of total Tcf4 levels in wt Hdh cells. Similarly, transcripts encoding isoforms TCF4-B and TCF4-C were reduced to $30 \%$, and transcripts encoding TCF4-A to $40 \%$ in $\mathrm{Hdh}^{109 / 109}$ cells in comparison with wt cells. TCF4-D-encoding mRNAs are transcribed from seven alternative $5^{\prime}$ exons out of which we analyzed transcripts with $8 c-/ / 5$ 'exon (Fig. 1C). No significant change in TCF4-D-encoding $8 c$-// transcript levels were detected (Fig. 2G).

To validate our findings from genetic HD model cell lines, we studied Tcf4 mRNA levels in an induced chemical model, cultured neurons treated with mitochondrial toxin 3-NP. We treated rat cortical neuron cultures with $0.5 \mathrm{~mm}$ 3-NP at DIV6-DIV8 for $0-16 \mathrm{~h}$ to mimic HD $(n=5)$. We determined the same Tcf4 transcripts as in Hdh cells. Total Tcf4 mRNA levels decreased in cultured cortical neurons after 8- and 16-h treatment with 3-NP to $60 \%$ of Tcf4 levels measured in untreated neurons (Fig. $2 H$ ). We observed reduction of TCF4-B and TCF4-C encoding mRNAs in response to 3-NP treatment. After 8- or 16-h exposure to 3-NP the levels of TCF4-A encoding mRNAs were decreased to $64 \%$ or to $85 \%$ of the levels detected in untreated neurons, respectively. Again, we measured levels of $8 c-/ /$ transcript as a representative of transcripts encoding TCF4-D and observed a 50\% decrease following 3-NP treatment.

Taken together, the levels of Tcf4 transcripts are reduced in cortical neurons treated with 3-NP as well as in HD striatal cell lines. This is consistent with the reduced protein levels of TCF4 in HD striatal cells.

\section{Differential downregulation of Tcf4 transcripts in R6/1 mouse brain}

Progressive neurodegeneration in HD is most prevalent in striatum and cerebral cortex, but other brain structures and circuits may also be affected (McColgan and Tabrizi,
2018). To extend our finding in HD cells to animal models, we decided to study Tcf4 mRNA levels in the transgenic $\mathrm{R} 6 / 1$ mouse model of $\mathrm{HD}$, where $\mathrm{N}$-terminal exon 1-containing fragment of human mutant huntingtin with 115 CAG repeats is expressed. We analyzed mRNA levels in the striatum, cortex, hippocampus and cerebellum of wt and $R 6 / 1$ mouse at $8,12,20$, and 30 weeks of age.

To study in detail Tcf4 mRNA expression in R6/1 mouse brain we quantified mRNA levels of total Tcf4, combination of the longer transcripts encoding TCF4-B and TCF4$C$ (TCF4-B/C), transcripts encoding only TCF4-B, and the most prevalent shorter transcripts encoding TCF4-D, TCF4-A, and TCF4-I by RT-qPCR (Fig. 3). There was no change in the total levels of Tcf4 mRNAs in the cerebral cortex, striatum and cerebellum, whereas downregulation of total Tcf4 expression was seen in the hippocampus of R6/1 mice when compared with wt mice at all the ages analyzed. More changes were detected in R6/1 mouse brain at the level of alternative transcripts with decreased longer transcripts encoding TCF4-B and TCF4-B/C in the hippocampus, transcripts encoding TCF4-A in the cerebral cortex and transcripts encoding TCF4-I in the cerebral cortex, hippocampus and striatum. Out of the studied TCF4-D encoding transcripts the expression of $8 c-1 /$ mRNA was downregulated and $7 b-I$ upregulated in the cerebral cortex and hippocampus of mutant versus wt mice. To sum up, we observed a reduction in total Tcf4 mRNA levels in R6/1 mouse hippocampus, and a comprehensive study revealed an intriguing variability and specific upregulations and downregulations of certain Tcf4 transcripts already before the onset of HD symptoms. Changes at the level of alternative Tcf 4 transcripts in the cerebral cortex and striatum, and no differences in the Tcf4 expression in the cerebellum were observed over a time course, from 8 to 30 weeks of age, in R6/1 compared with wt mouse.

\section{TCF4 protein levels are decreased in the hippocampus of $\mathrm{R} 6 / 1$ mouse}

We next asked whether the changes detected in Tcf4 mRNA expression were reflected in the levels of TCF4 protein isoforms in R6/1 mouse brain. We analyzed TCF4 protein levels by Western blotting with monoclonal TCF4 antibody c-8 in the striatum, cortex and hippocampus in the same mice where Tcf4 mRNA levels were analyzed. The quality of Western blottings enabled quantification of the separate TCF4 bands that were assigned as potential B/C, $D, A^{-}$, and $A^{+}$isoforms in the order of increasing mobility in PAGE based on theoretical $\mathrm{Mw}$ and comparisons with in vitro translated TCF4 isoforms (Fig. $2 C, E$ ). No band corresponding to TCF4-I was detected. The patterns of TCF4 isoforms expressed in the two pallial structures, cerebral cortex and hippocampus, were similar, whereas in the subpallial striatum the relative proportions of TCF4-D were lower (Fig. $4 B, D)$. Comparisons of TCF4 isoform levels across wt and transgenic mice revealed decreased levels of TCF4- $\mathrm{A}^{-}$in the R6/1 mouse cerebral cortex and a reduction of TCF4-B/C and TCF $4-D$ by $30 \%$ and $40 \%$, respectively, in R6/1 mouse hippocampus at all the ages analyzed (Fig. 4D). No statistically significant differences were detected in the striatum. 


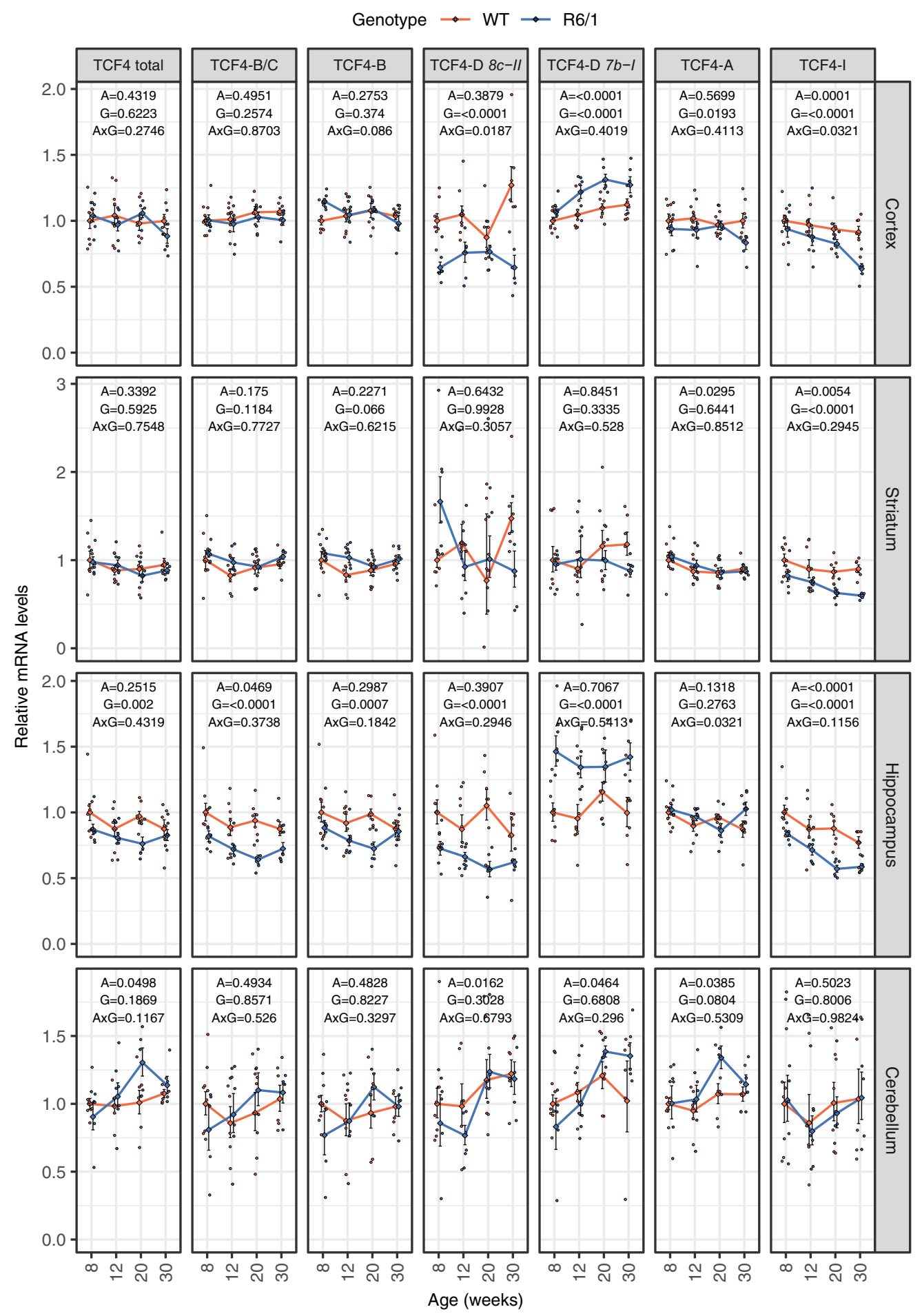

Figure 3. Tcf4 mRNA levels in R6/1 mouse brain. RT-qPCR analysis of mRNA levels of total Tcf4 and selected Tcf4 transcripts encoding alternative TCF4 isoforms. RT-qPCR analysis was conducted in cortex, striatum, hippocampus, and cerebellum from wt and R6/1 mice at four ages $(8,12,20$, and 30 weeks of age). Number of samples included in each experiment is indicated in Table 4. The transcripts encoding long isoforms TCF4-B and TCF4-C were measured together (TCF4-B/C) and separately in the case of TCF4-B; two TCF4-D encoding transcripts $8 c-I I$, and $7 b-I$ as well as transcripts encoding short isoforms TCF4-A, and TCF4-I were quantified. Tcf4 mRNA levels were normalized to geometric mean of the levels of Hprt1, Tbp, and Gapdh. The average expression level of respective transcript in eight-week-old wt animals was set as 1 . The average expression of the respective transcripts in respective groups is shown with lines, error bars indicate SEM, data from all individual animals are shown with dots. Generalized linear model using the formula age + genotype + age:genotype was used, followed by Wald $\chi^{2}$ test to determine $p$ values of the coefficients (shown at the top of each graph). A, age; G, genotype; $A \times G$, interaction between age and genotype. 
A
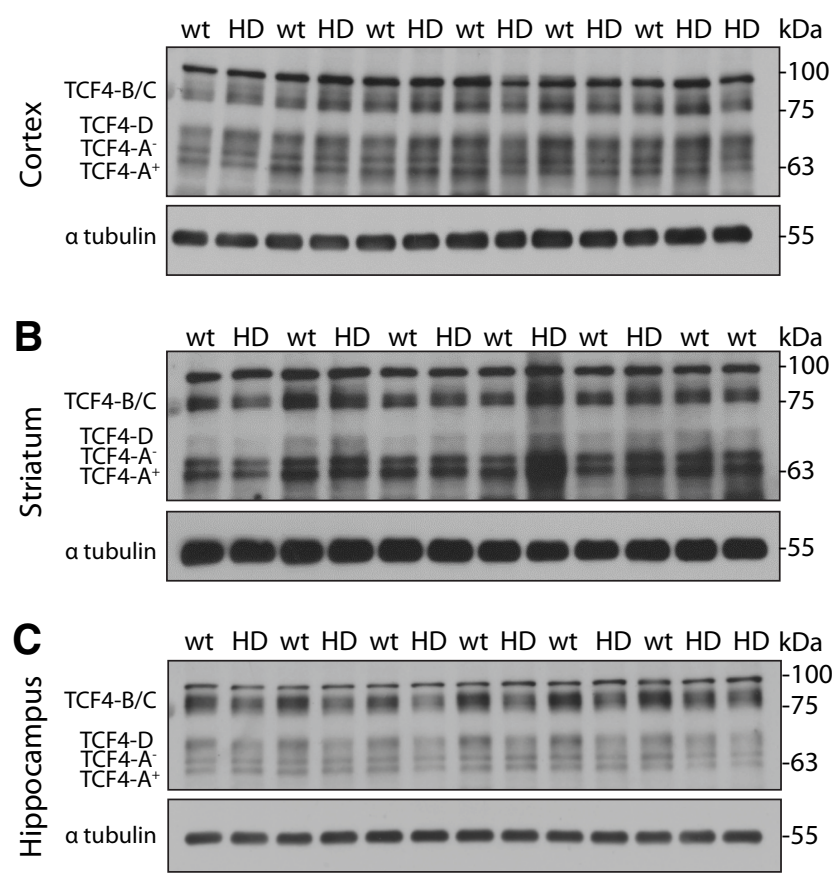

E

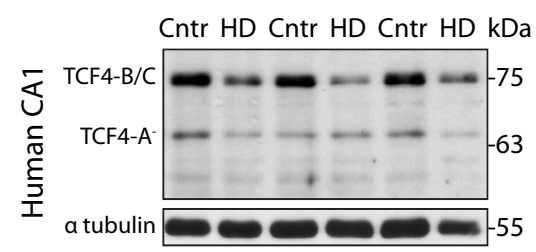

$\mathbf{F}$

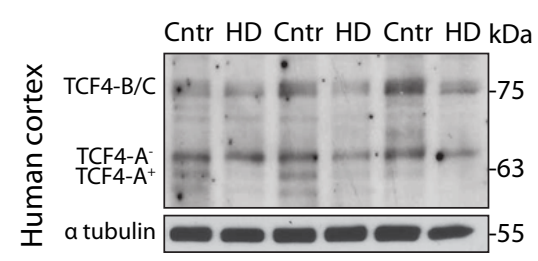

D
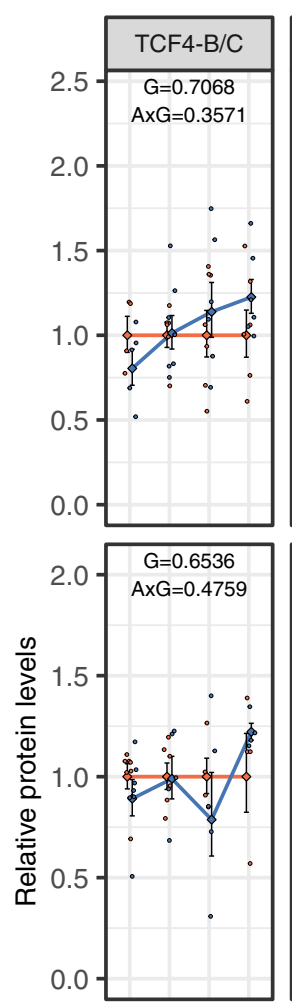

G

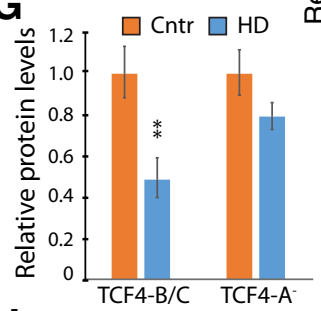

H
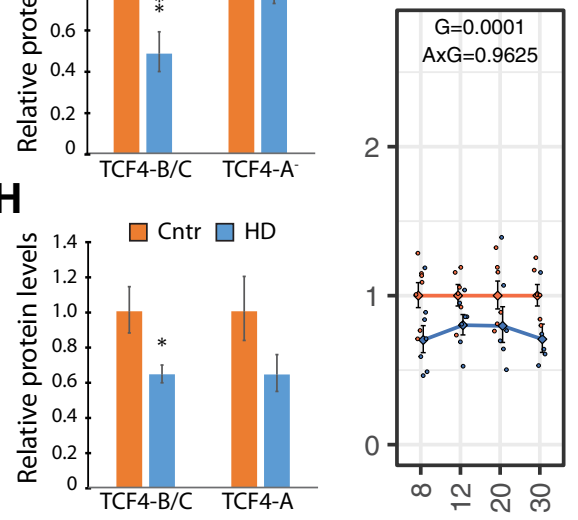

Genotype $\leadsto$ WT $\rightarrow$ R6/1
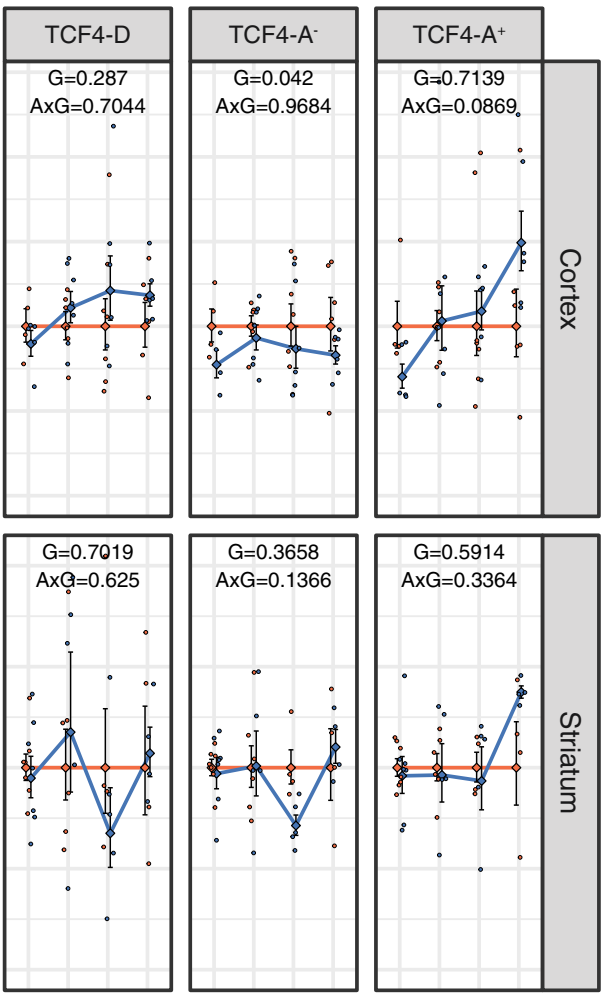
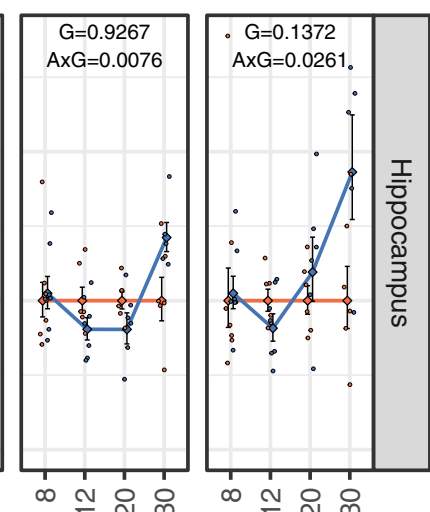

Age (weeks)

Figure 4. TCF4 protein levels in different brain regions of R6/1 mouse and HD patients. $\boldsymbol{A}-\boldsymbol{C}$, Western blot analysis of TCF4 protein levels in wt and R6/1 mouse cerebral cortex $(\boldsymbol{A})$, striatum $(\boldsymbol{B})$, and hippocampus $(\boldsymbol{C})$ at 12 weeks of age (blots not shown for 8 , 20, and 30 weeks of age). $\alpha$ tubulin served as loading control. $\boldsymbol{D}$, Quantifications of Western blotting data. Number of samples included in each experiment is indicated in Table 4. The average expression level of the respective isoform in wt animals of each age group was set as 1. The average expression of the respective isoform in respective groups is shown with lines, error bars indicate SEM, data from all individual animals are shown with dots. Generalized linear model using the formula genotype + age:genotype was used, followed by Wald $\chi^{2}$ test to determine $p$ values of the coefficients (shown at the top of each graph), with $\mathrm{G}$ designating genotype, and $A \times G$ designating interaction between age and genotype. $\boldsymbol{E}, \boldsymbol{F}$, Representative Western blot analysis of TCF4 protein levels in human hippocampal CA1 region and cerebral cortex, respectively, of healthy controls (Cntr) and HD patients (HD). $\alpha$ tubulin served as loading control. Human postmortem samples are described in Table 1. G, H, Quantification of data in $\boldsymbol{E}$, $\boldsymbol{F}$, respectively, and additional Western blottings (data not shown). For human hippocampal CA1 region a total of seven healthy controls and $10 \mathrm{HD}$ patients were analyzed, and for human cortex, six healthy controls and six HD patients were analyzed. TCF4 signal intensities were normalized to $\alpha$ tubulin signal intensities. The relative TCF4 levels in healthy controls were arbitrarily set as 1 . Data were log-transformed, means and SEMs were calculated, and two-tailed two-sample equal variance $t$ test was used. Data were back-transformed into the linear scale for graphical representation, error bars represent upper and lower limits of back-transformed mean \pm SEM; ${ }^{*} p<0.05,{ }^{* *} p<0.01$; precise $p$ values are stated in Extended Data Figure $4-1$. 
A

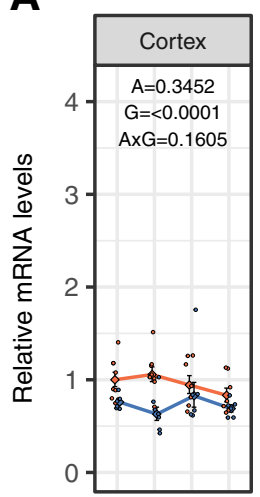

Genotype $\multimap$ WT $\rightarrow$ R6/1

B

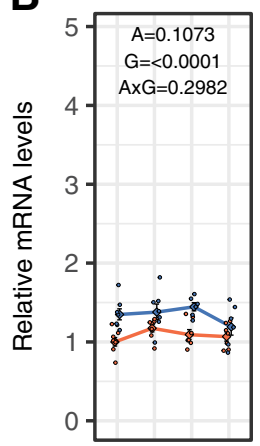

C

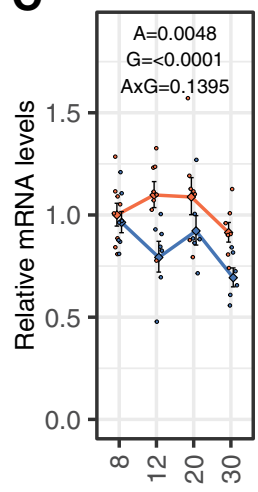

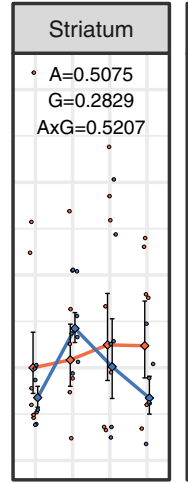
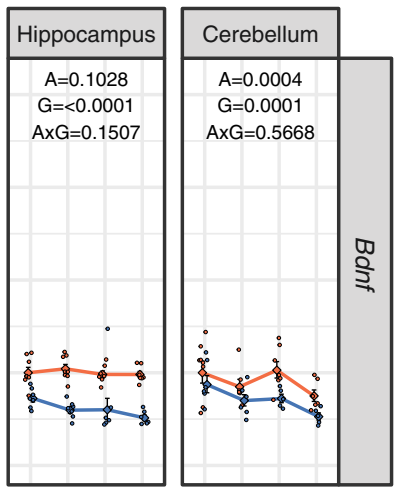

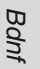
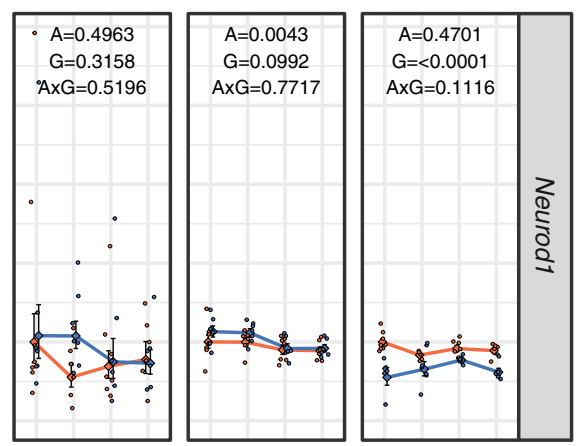

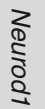
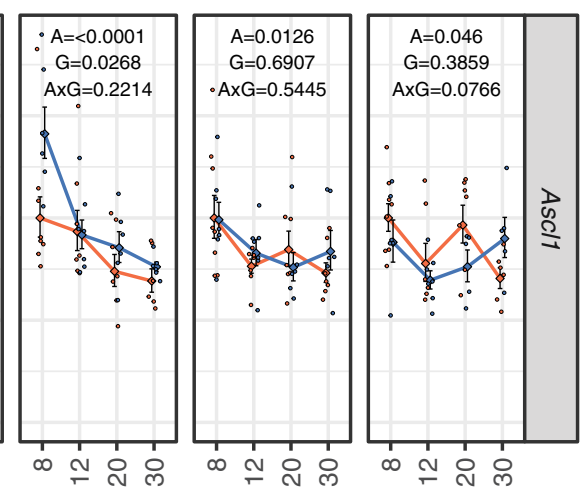

Age (weeks)

Collectively, the results of Western blot analysis in R6/1 mouse brain are in good agreement with the major effects seen for Tcf4 mRNA levels, further indicating that the changes in TCF4 are isoform and brain region specific.

\section{High Mw isoforms of TCF4 are decreased in HD patient's hippocampus}

We observed downregulation of several Tcf4 transcripts and protein isoforms in R6/1 mouse hippocampus and cerebral cortex, therefore we next analyzed TCF4 protein levels in these regions of HD patients. Tissue lysates of hippocampal CA1 region and cerebral cortex from postmortem HD patients and neurologically healthy controls were analyzed by Western blotting using monoclonal antiTCF4 antibody c-8. The expression pattern of TCF4 protein isoforms in human brain tissues differed from mouse, although bands likely corresponding to TCF4-B/C and TCF4-A could be detected (Fig. 4E,F). TCF4 high Mw isoforms TCF4-B/C were significantly reduced in the hippocampus of HD patients (Fig. 4E,G), while the expression of shorter isoforms, likely TCF4- $A^{-}$, was not significantly changed (Fig. 4G). We detected statistically significant reduction of TCF4-B/C in the cerebral cortex of HD patients and decreased levels of TCF4-A (sum of TCF4- $\mathrm{A}^{-}$and TCF4- $\mathrm{A}^{+}$) that did not reach to statistical significance (Fig. $4 F, H)$. Decreased TCF4 levels in human hippocampus and cerebral cortex corroborate our findings in R6/1 mouse, suggesting dysregulation of TCF4 expression in HD hippocampus and cortex in both mice and humans.

\section{Differential expression of BDNF and TCF4 dimerization partners in $\mathrm{R} 6 / 1$ mouse brain}

The reduction of wt HTT and expression of mutant HTT have been shown to decrease the levels of the neurotrophic factor BDNF (Zuccato et al., 2001), and this decrease has been observed in many HD models as well as in HD patients (Ferrer et al., 2000; Duan et al., 2003; Zhang et al., 2003). It has also been reported that TCF4 regulates BDNF expression through an enhancer region (Tuvikene et al., 2021). To this end, we quantified Bdnf mRNA levels in the $R 6 / 1$ different brain regions (Fig. $5 A$ ). Our analysis revealed that the presence of mutant $\mathrm{HTT}$ significantly affects the expression of Bdnf gene in R6/1 mouse cerebral cortex, hippocampus and cerebellum. No change of $B d n f$ mRNA levels was detected in R6/1 mouse striatum. Moreover, the expression level of Bdnf mRNA was very low in the striatum compared with other brain regions studied, which is in line with the knowledge that Bdnf expression is very limited in the striatum and most of striatal BDNF protein is anterogradely transported there from the cortex (Altar et al., 1997). Collectively, Bdnf mRNA levels were reduced in the brain of $R 6 / 1$ mouse used in this study, possibly partially because of decreased TCF4 levels in this model system.

Transcription factor TCF4 belongs to E-protein family of bHLH transcription factor superfamily that bind E-box DNA sequence as homodimers or heterodimers. TCF4 is one of the three E-protein partners for proneural 
transcription factor ASCL1 and neuronal differentiation factor NEUROD1 (Massari and Murre, 2000; Dennis et al., 2019) that display altered gene expression in HD iPSC cells (The HD iPSC Consortium, 2017). Therefore, we determined mRNA levels of these dimerization partners in the $\mathrm{R} 6 / 1$ mouse brain regions. While the biggest decrease of many Tcf 4 mRNAs were detected in hippocampus of R6/1 mouse, mRNA levels of Neurod1 and Asc/1 were not affected in this brain region (Fig. 5B,C). Along with downregulation of several short Tcf4 transcripts, the levels of Ascl1 mRNA were reduced (Fig. 5B), whereas Neurod1 mRNA was upregulated in $\mathrm{R} 6 / 1$ mouse cerebral cortex when compared with wt mice (Fig. 5B). Unchanged mRNA levels of Neurod1 in the striatum and downregulated levels in the cerebellum were paralleled with almost unchanged mRNA levels of Tcf4 in these regions (Fig. 5B). Additionally, the mRNA levels of Ascl1 were increased in the striatum of R6/1 mouse in comparison to wt mice (Fig. $5 C)$, whereas there was no significant change of Ascl1 mRNA levels in the cerebellum (Fig. 5C). Collectively, the analysis of the two TCF4 dimerization partners indicate that their expression is also dysregulated in the R6/1 HD mouse model, although in a different regional pattern compared with TCF4, implying a wide-spread dysregulation of E-box-dependent transcription, even in brain regions where TCF4 was not affected.

\section{TCF4 and ASCL1 synergistically transactivate reporter gene transcription in rat cortical and hippocampal neurons}

Different transactivation capacity of specific TCF4 protein isoforms has been reported in HEK293 cells and in mixed culture of rat cortical and hippocampal neurons (Sepp et al., 2011, 2012, 2017). Additionally, TCF4-A ${ }^{-}$activates Gadd45g promoter in co-operation with ASCL1 in unstimulated and $\mathrm{KCl}$-depolarized neurons (Sepp et al., 2017). Here, we observed notable cortex and hippocampus-specific differences in the expression of different TCF4 isoforms and Ascl1 between wt and R6/1 mouse. Therefore, we set out to comprehensively study the transactivation capability of major TCF4 protein isoforms and their synergism with dimerization partner ASCL1 separately in hippocampal and cortical neurons before and after induction of neuronal activity. For this, we transfected neurons with E-box-dependent luciferase reporter, together with different TCF4 isoform-encoding and ASCL1-encoding constructs. To mimic neuronal activity, cells were chronically depolarized using $\mathrm{KCl}$. In unstimulated cells overexpressing TCF4 alone, all TCF4 protein isoforms induced reporter gene expression to relatively similar extent, except TCF4-I ${ }^{-}$that induced reporter gene expression three times less compared with full-length isoform TCF4-B ${ }^{-}$in both cortical and hippocampal neurons (Fig. $6 A, B$ ). $\mathrm{KCl}$ treatment induced TCF4-dependent transcription on average 2-fold over basal activity levels of the same TCF4 isoform, with no major differences between TCF4 isoforms. In contrast, co-expression of TCF4 and ASCL1 revealed differential upregulation of reporter activity (Fig. 6A,B). TCF4-B showed minimal increase of reporter activation in co- operation with ASCL1, whereas 20-fold increase over TCF4-I' alone was seen when TCF4-I' and ASCL1 were expressed together. We also noted that reporter activity was higher when co-expressing ASCL1 with different TCF4 isoforms in cortical neurons compared with hippocampal neurons. The reporter gene expression was further induced by $\mathrm{KCl}$ treatment in cells co-expressing TCF4 and ASCL1. However, the total reporter gene expression level was drastically lower in TCF4-B ${ }^{-}$overexpressing neurons compared with other TCF4 isoforms under the same conditions. The highest reporter expression was seen with the shortest TCF4 isoform TCF4-I co-expressed with ASCL1 and treated with $\mathrm{KCl}$, where its low initial transactivation capacity was more than fully compensated. To analyze transcriptional synergy between TCF4 and ASCL1, we calculated co-operation indices according to Chang et al. (1996). All TCF4 isoforms had a synergistic effect with ASCL1 in both cortical and hippocampal neurons (6C and 6D). The co-operation was the smallest for TCF4-B ${ }^{-}$, equally high for TCF4- $\mathrm{C}^{-}$, TCF4-D', and TCF4-A', and exceptionally high for TCF4$\mathrm{I}^{-}$. Additionally, $\mathrm{KCl}$ treatment increased the synergism between TCF4 isoforms and ASCL1 in hippocampal neurons, but not in cortical neurons. To conclude, these results illustrate the TCF4 isoform-dependent differential transactivation in neurons and suggest brain region specific TCF4-dependent gene transcription. Furthermore, considering the brain region-specific dysregulation of TCF4 and its binding partners in HD, this differential synergism between TCF4 and its binding partners could also play a role in the etiology of HD.

\section{Discussion}

An increasing body of evidence suggests that HD is not only a neurodegenerative disease but also has a strong neurodevelopmental component (The HD iPSC Consortium, 2017; Siebzehnrübl et al., 2018; Barnat et al., 2020). Here, we set out to study TCF4 in the context of HD. Haploinsufficiency of TCF4 causes a rare neurodevelopmental Pitt-Hopkins syndrome, TCF4 has been linked to schizophrenia and mild to moderate intellectual disability, and has been shown to regulate neurogenesis, synaptic plasticity, memory and DNA methylation (Zweier et al., 2007; Blake et al., 2010; Kennedy et al., 2016; Jung et al., 2018; Page et al., 2018; Li et al., 2019). Here, we demonstrate that the expression of TCF4 is dysregulated in both cellbased and animal models of HD and in HD patients.

TCF4 can regulate target gene expression both as homodimers and as heterodimers with class II proneural bHLH proteins such as ASCL1 and NEUROD1. ASCL1 is considered to have several functions in neurogenesis, for example it is important in preserving the pool of nerve cell progenitors, whereas NEUROD1 plays important roles in neuronal and glial differentiation and maturation (for review, see Dennis et al., 2019). In R6/1 mouse cerebral cortex we found that Neurod1 mRNA levels were increased, Asc/1 mRNA levels were decreased, and total levels of Tcf4 transcripts remained unchanged. Additionally, in the cerebral cortex we detected decreased TCF4-A ${ }^{-}$protein in $\mathrm{R} 6 / 1$ mice and TCF4-B/C proteins in $\mathrm{HD}$ patients. 
A

Cortical neurons

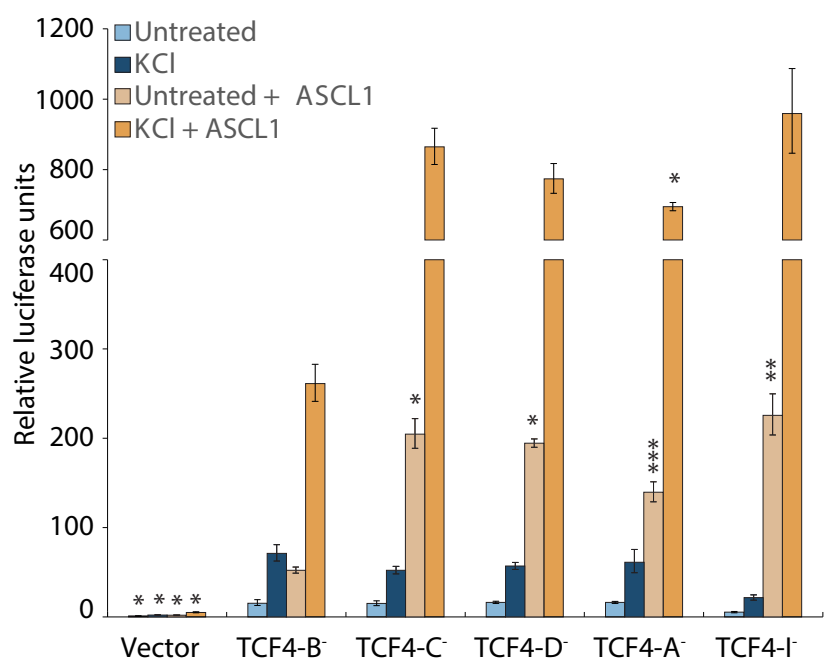

C

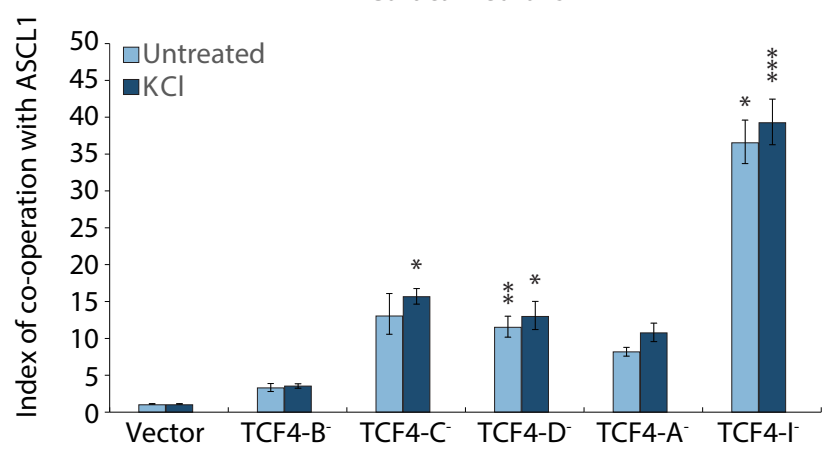

B

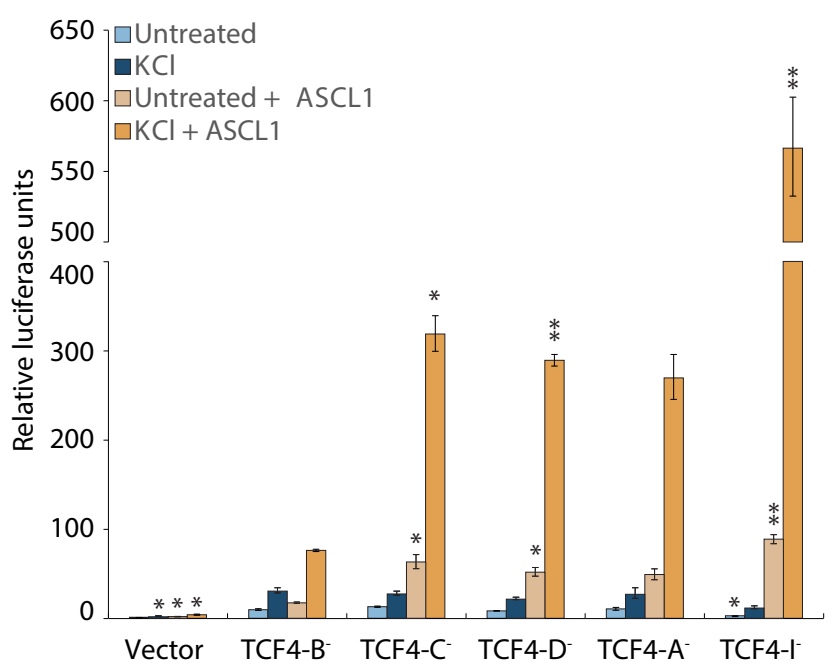

D

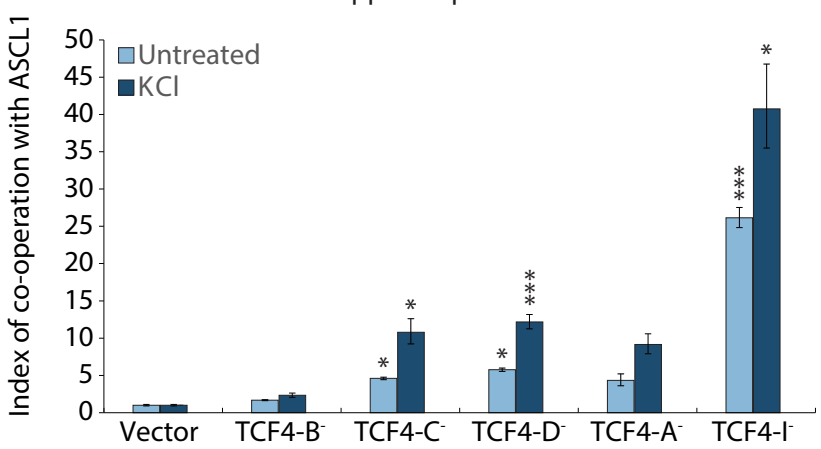

Figure 6. Differential co-operation of TCF4 isoforms with ACSL1 in cortical and hippocampal neurons. $\boldsymbol{A}, \boldsymbol{B}$, Specific TCF4 isoforms and ASCL1 under the control of EF1a and PGK1 promoter, respectively, were overexpressed in rat primary cortical (A) or hippocampal $(\boldsymbol{B})$ neurons at 6 DIV. For luciferase reporter assay, the cells were co-transfected with firefly luciferase reporter construct with 12 $\mu \mathrm{E} 5 \mathrm{E}$-boxes (CACCTG) in front of TK promoter, and for normalization Renilla luciferase construct with PGK1 promoter was used. One day after transfection, neurons were treated with $25 \mathrm{~mm} \mathrm{KCl}$ for $8 \mathrm{~h}$ or left untreated. Luciferase signals from three independent experiments were measured in duplicates, normalized to Renilla signals, log-transformed, mean-centered, and autoscaled for statistical analysis. Data were back-transformed to original scale and are presented relative to the signals measured from empty vectortransfected (Vector) untreated cells (arbitrarily set 1). C, $\boldsymbol{D}$, Index of co-operation between TCF4 isoforms and ASCL1 in basal and depolarized conditions calculated from data in $\boldsymbol{A}$ or $\boldsymbol{B}$, respectively. Normalized luciferase data were used for calculating co-operation indices, data were log-transformed, mean-centered and autoscaled for statistical analysis and back-transformed for graphical depiction. The index value of 1 implies simple summation, while values above 1 indicate synergism and below 1 antagonism. The co-operation is expressed separately for untreated or KCl-treated cells. A-D, Error bars indicate SEM. One-way ANOVA followed by Tukey's post hoc test was used for statistical analysis (precise $p$ values are reported in Extended Data Figure 6-1). Asterisks show statistical significance relative to cells overexpressing TCF4- $\mathrm{B}^{-}$in basal conditions $(\boldsymbol{A}, \boldsymbol{B})$. For cooperation indexes, statistical significance is shown within untreated or $\mathrm{KCl}$-treated cells relative to TCF4- $\mathrm{B}^{-}$in the respective condition $(\boldsymbol{C}, \boldsymbol{D}$; precise $p$ values are reported in Extended Data Figure 6-1); ${ }^{*} p<0.05,{ }^{* *} p<0.01,{ }^{* *} p<0.001$.

These detected changes of transcription factors might explain why the developing cerebral cortex of mutant HTTexpressing human fetuses present diminishing pool of proliferating cells and neural progenitors enter prematurely neuronal lineage specification (Barnat et al., 2020). We also found disease-dependent downregulation of Neurod1 in the cerebellum and no significant expression change in the hippocampus of R6/1 mice, in combination with unchanged or drastically decreased Tcf4 mRNA levels in cerebellum and hippocampus, respectively.
NEUROD1 has functions in granule cells of these two brain regions (Miyata et al., 1999; Pleasure et al., 2000; Gao et al., 2009), and co-expression of NEUROD1 and TCF4 has been demonstrated in adult mouse DG immature granule neurons (Jung et al., 2018). Moreover, decreased protein levels of NEUROD1 were reported to affect neurogenesis in the adult hippocampus of the R6/2 mice, a fast-progressing HD model (Fedele et al., 2011). The study of HD patient-derived iPSC induced into mixed neural phenotypes showed that one-third of gene 
changes were in pathways regulating neuronal development and maturation, and downregulation of NEUROD1 and ASCL1 were also reported (The HD iPSC Consortium, 2017). Taken together, we showed HD-dependent brain region-specific altered expression levels of proneural Ascl1 and Neurod1 in adult mice with known relevant functions in these brain tissues. Delineating the expression of these transcription factors at earlier developmental stages of R6/1 mice could be of interest for future studies.

The human TCF4 gene structure has been described by Sepp et al. (2011), and here we report a detailed description of mouse Tcf4 gene structure and the numerous transcripts it encodes. The gene structure of TCF4 is conserved between species suggesting functional relevance of potential protein isoforms. In general, the functions of alternative TCF4 isoforms are poorly studied and the reason for multitude of 5 "exons with specific promoters, isoforms with $\mathrm{N}$ termini of different length, and $+/$ - isoforms of TCF4 is still a puzzle. One of the early studies of TCF4 (known previously as E2-2, SEF2-1, and ITF2) revealed that TCF4-D inhibits MYOD (Skerjanc et al., 1996), and another study showed specific inhibition of brain-specific FGF1B by TCF4-B ${ }^{-}$, whereas TCF4-B ${ }^{+}$did not have any effect (Liu et al., 1998). Furthermore, differential expression was shown for Tcf4-A and Tcf4-B in immune cell types, and isoform-specific regulation was shown for normal plasmacytoid dendritic cell development (Grajkowska et al., 2017). Recently, discrepant effects of TCF4 isoforms $B$ and $A$ were shown in the context of oligodendrocytes differentiation, and the authors propose that the differentiation promoting effect of TCF4 is specific to the long isoform (Wedel et al., 2020). Additionally, alternative TCF4 isoforms have differential transactivation potential in HEK293 cells and also in unstimulated and depolarized neurons (Sepp et al., 2011, 2017). Here, we report isoform-dependent co-operation of TCF4 with ASCL1 in neurons. Although functional dimerization of TCF4 and ASCL1 has been shown previously (Persson et al., 2000; de Pontual et al., 2009; Sepp et al., 2017), there is limited knowledge of their co-operation to activate transcription in neurons, specifically in cortical and hippocampal neurons. We found that there is a synergistic effect between all studied TCF4 protein isoforms and ASCL1, although extent of the synergy varies several times depending on the TCF4 protein isoform. For example, the low transactivation capability of TCF4-I' overexpressed alone (probably mainly homodimers) is compensated when heterodimerized with ASCL1, whereas full-length TCF4-Bshows limited synergism with ASCL1. Furthermore, we saw a depolarization-dependent increase in TCF4-ASCL1 synergy in hippocampal but not in cortical neurons. This suggests that the neuronal activity-dependent transcriptional regulation of TCF4 and its heterodimers could be fundamentally different in different brain regions and neuron populations. This could be relevant for developing alleviating therapies for diseases and disorders with disturbances of distinct TCF4 isoforms in specific brain regions affected as we have reported here for HD.

Highly similar total TCF4 expression patterns have been reported for humans, rhesus monkeys, and mice at total
TCF4 level (Jung et al., 2018). TCF4 is involved in the early stages of neuronal development and highly expressed across the entire brain (Kim et al., 2020). In contrast, in adult brain the high expression of TCF4 is restricted to the pallial region and cerebellum (Kim et al., 2020). Here, we observed brain region-specific differences in the proportions of TCF4 isoforms expressed in mice, and our Western blot analysis of human TCF4 in the hippocampus and cerebral cortex of elderly adults showed a distinctive pattern of TCF 4 isoforms divergent from that seen in adult mice. Importantly, we have validated all used TCF4 antibodies in Tcf4 KO mice embryonic cortical tissue lysates, therefore we believe that bands detected on human immunoblot are specific. Additionally, we validated TCF4 antibodies with several in vitro translated human TCF4 isoforms, however, we cannot completely rule out the possibility of masking TCF4 isoform specific signals by other proteins with similar apparent Mw in Western blotting using human tissue lysates. Nevertheless, differential subcellular and brain region-specific expression of TCF4 isoforms suggests fine-tuning of expression, likely required for precisely controlled target gene expression. In our RT-qPCR study of Tcf 4 transcripts in R6/1 mice, we observed opposite change in the levels of TCF4-D encoding $8 c-I /$ and $7 b-I$ mRNAs. This additional layer of complexity entails potential to differentially regulate multitude of $5^{\prime}$ alternative TCF4 transcripts that eventually translate into the same TCF4 isoform. Our results indicate that the possibility of specific regulation is not a mere opportunity, but these transcripts actually are expressed differentially in $\mathrm{R} 6 / 1$ mouse hippocampus and cortex.

The most notable result of our study is the decreased levels of TCF4, a neurodevelopmentally important transcription factor, in the hippocampus and cerebral cortex of both HD mouse model and HD patients. For a long time, the role of hippocampus in HD has been overlooked. However, recently its role in HD has been acknowledged as symptoms such as decline of cognitive functions and problems with learning new information most probably arise from dysfunctional hippocampal neurons and impaired synaptic plasticity and memory (Milnerwood et al., 2006; Puigdellívol et al., 2016; Smith-Dijak et al., 2019). Disease-dependent misregulation of BDNF and its downstream signaling pathways in HD models and patients have been well-described (Smith-Dijak et al., 2019) and $\mathrm{BDNF}$ is one of the master regulators of synaptic plasticity (Park and Poo, 2013). It has been shown that both loss of wt and gain of mutant HTT in HD decreases the levels of the neurotrophic factor BDNF (Zuccato et al., 2001, 2003; Gauthier et al., 2004) and increasing BDNF signaling rescues synaptic plasticity and memory in HD mice (Lynch et al., 2007; Anglada-Huguet et al., 2016). It has been recently reported that TCF4 regulates Bdnf expression (Tuvikene et al., 2021), and here we report downregulation of both TCF4 and Bdnf expression in the hippocampus and cerebral cortex of R6/1 mice. It is plausible that the downregulation of TCF4 could be one of the causal mechanisms underlying the downregulation of BDNF expression in the hippocampus and cerebral cortex of HD mouse models and patients in addition to the well- 
described NRSF-dependent mechanism (Zuccato et al., 2001, 2003, 2007; Conforti et al., 2013).

Spatial memory is believed to rely on adult hippocampal neurogenesis (Abrous and Wojtowicz, 2015) and impairment of spatial perception and spatial memory are reported in HD patients, correlating with their HD disease burden score (Harris et al., 2019). Additionally, R6/1 and R6/2 HD mice and the more slowly progressing YAC128 HD mice show reduced hippocampal adult neurogenesis in the SGZ of DG (Lazic et al., 2004; Gil et al., 2005; Simpson et al., 2011). Considering (1) the functions of TCF4 in neurogenesis (Schoof et al., 2020; Wang et al., 2020) and neural plasticity (Kennedy et al., 2016; Thaxton et al., 2018; Badowska et al., 2020); (2) high expression of TCF4 in hippocampal neuroepithelium and its persistence in all mature hippocampal neuron subpopulations and astrocytes and similar high expression in cortical structures (Jung et al., 2018; Kim et al., 2020); and (3) downregulation of TCF4 we show here in R6/1 mouse and HD patient hippocampus and cerebral cortex, allows to hypothesize that TCF4 might play a role in the impairment of cognitive functions in $\mathrm{HD}$. In R6/1 mice, the motor and cognitive symptoms generally appear at 12-20 weeks of age (Naver et al., 2003; Bolivar et al., 2004; Giralt et al., 2013), and treatment with papaverin (inhibitor of PDE10a) or betulinic acid improve these symptoms (Giralt et al., 2013; AlcaláVida et al., 2021). Importantly, both of these compounds affect PKA and cAMP levels, which are known to increase TCF4 transcriptional activity (Sepp et al., 2017). It is tempting to speculate that this effect could be, at least partially, be because of the increased TCF4-dependent gene expression.

To conclude, we have identified TCF4 as a dysregulated transcription factor in HD and provided evidence for the brain region-dependent regulation and functions of alternative TCF4 isoforms. Future work will elucidate the functional role of this dysregulation.

\section{References}

Abrous DN, Wojtowicz JM (2015) Interaction between neurogenesis and hippocampal memory system: new vistas. Cold Spring Harb Perspect Biol 7:a018952.

Aimone JB, Wiles J, Gage FH (2009) Computational influence of adult neurogenesis on memory encoding. Neuron 61:187-202.

Alcalá-Vida R, Garcia-Forn M, Castany-Pladevall C, Creus-Muncunill J, Ito Y, Blanco E, Golbano A, Crespí-Vázquez K, Parry A, Slater G, Samarajiwa S, Peiró S, Di Croce L, Narita M, Pérez-Navarro E (2021) Neuron type-specific increase in lamin B1 contributes to nuclear dysfunction in Huntington's disease. EMBO Mol Med 13: e12105.

Altar CA, Cai N, Bliven T, Juhasz M, Conner JM, Acheson AL, Lindsay RM, Wiegand SJ (1997) Anterograde transport of brainderived neurotrophic factor and its role in the brain. Nature 389:856-860.

Ament SA, Pearl JR, Cantle JP, Bragg RM, Skene PJ, Coffey SR, Bergey DE, Wheeler VC, MacDonald ME, Baliga NS, Rosinski J, Hood LE, Carroll JB, Price ND (2018) Transcriptional regulatory networks underlying gene expression changes in Huntington's disease. Mol Syst Biol 14:e7435.

Anglada-Huguet M, Vidal-Sancho L, Giralt A, García-Díaz Barriga G, Xifró X, Alberch J (2016) Prostaglandin E2 EP2 activation reduces memory decline in R6/1 mouse model of Huntington's disease by the induction of BDNF-dependent synaptic plasticity. Neurobiol Dis 95:22-34.

Badowska DM, Brzózka MM, Kannaiyan N, Thomas C, Dibaj P, Chowdhury A, Steffens H, Turck CW, Falkai P, Schmitt A, Papiol S, Scheuss V, Willig KI, Martins-de-Souza D, Rhee JS, Malzahn D, Rossner MJ (2020) Modulation of cognition and neuronal plasticity in gain- and loss-of-function mouse models of the schizophrenia risk gene Tcf4. Transl Psychiatry 10:343.

Bae BI, Xu H, Igarashi S, Fujimuro M, Agrawal N, Taya Y, Hayward SD, Moran TH, Montell C, Ross CA, Snyder SH, Sawa A (2005) p53 mediates cellular dysfunction and behavioral abnormalities in Huntington's disease. Neuron 47:29-41.

Barnat M, Capizzi M, Aparicio E, Boluda S, Wennagel D, Kacher R, Kassem R, Lenoir S, Agasse F, Braz BY, Liu JP, Ighil J, Tessier A, Zeitlin SO, Duyckaerts C, Dommergues M, Durr A, Humbert S (2020) Huntington's disease alters human neurodevelopment. Science 369:787-793.

Bates GP, Dorsey R, Gusella JF, Hayden MR, Kay C, Leavitt BR, Nance M, Ross CA, Scahill RI, Wetzel R, Wild EJ, Tabrizi SJ (2015) Huntington disease. Nat Rev Dis Primers 1:15005.

Blake DJ, Forrest M, Chapman RM, Tinsley CL, O'Donovan MC, Owen MJ (2010) TCF4, schizophrenia, and Pitt-Hopkins syndrome. Schizophr Bull 36:443-447.

Bolivar VJ, Manley K, Messer A (2004) Early exploratory behavior abnormalities in R6/1 Huntington's disease transgenic mice. Brain Res 1005:29-35.

Cha JHJ (2007) Transcriptional signatures in Huntington's disease. Prog Neurobiol 83:228-248.

Chambers RA, Potenza MN, Hoffman RE, Miranker W (2004) Simulated apoptosis/neurogenesis regulates learning and memory capabilities of adaptive neural networks. Neuropsychopharmacology 29:747-758.

Chang W, Zhou W, Theill LE, Baxter JD, Schaufele F (1996) An activation function in Pit-1 required selectively for synergistic transcription. J Biol Chem 271:17733-17738.

Conforti P, Mas Monteys A, Zuccato C, Buckley NJ, Davidson B, Cattaneo E (2013) In vivo delivery of DN: REST improves transcriptional changes of REST-regulated genes in HD mice. Gene Ther 20:678-685.

de Pontual L, Mathieu Y, Golzio C, Rio M, Malan V, Boddaert N, Soufflet C, Picard C, Durandy A, Dobbie A, Heron D, Isidor B, Motte J, Newburry-Ecob R, Pasquier L, Tardieu M, Viot G, Jaubert F, Munnich A, Colleaux L, et al. (2009) Mutational, functional, and expression studies of the TCF4 gene in Pitt-Hopkins syndrome. Hum Mutat 30:669-676.

Dennis DJ, Han S, Schuurmans C (2019) bHLH transcription factors in neural development, disease, and reprogramming. Brain Res 1705:48-65.

Duan W, Guo Z, Jiang H, Ware M, Li X-J, Mattson MP (2003) Dietary restriction normalizes glucose metabolism and BDNF levels, slows disease progression, and increases survival in huntingtin mutant mice. Proc Natl Acad Sci USA 100:2911-2916.

Dunah AW, Jeong H, Griffin A, Kim Y-M, Standaert DG, Hersch SM, Mouradian MM, Young AB, Tanese N, Krainc D (2002) Sp1 and TAFII130 transcriptional activity disrupted in early Huntington's disease. Science 296:2238-2243.

Esvald EE, Tuvikene J, Sirp A, Patil S, Bramham CR, Timmusk T (2020) CREB family transcription factors are major mediators of BDNF transcriptional autoregulation in cortical neurons. J Neurosci 40:1405-1426.

Fedele V, Roybon L, Nordström U, Li JY, Brundin P (2011) Neurogenesis in the R6/2 mouse model of Huntington's disease is impaired at the level of NeuroD1. Neuroscience 173:76-81.

Ferrer I, Goutan E, Marín C, Rey MJ, Ribalta T (2000) Brain-derived neurotrophic factor in Huntington disease. Brain Res 866:257261.

Forrest MP, Hill MJ, Kavanagh DH, Tansey KE, Waite AJ, Blake DJ (2018) The psychiatric risk gene transcription factor 4 (TCF4) regulates neurodevelopmental pathways associated with schizophrenia, autism, and intellectual disability. Schizophr Bull 44:11001110. 
Fox J, Weisberg S (2019) An R companion to applied regression, Ed 3. Los Angeles: SAGE.

Gao Z, Ure K, Ables JL, Lagace DC, Nave K-A, Goebbels S, Eisch AJ, Hsieh J (2009) Neurod1 is essential for the survival and maturation of adult-born neurons. Nat Neurosci 12:10.

Gauthier LR, Charrin BC, Borrell-Pagès M, Dompierre JP, Rangone $\mathrm{H}$, Cordelières FP, De Mey $\mathrm{J}$, MacDonald ME, Lessmann V, Humbert S, Saudou F (2004) Huntingtin controls neurotrophic support and survival of neurons by enhancing BDNF vesicular transport along microtubules. Cell 118:127-138.

Gil JMAC, Mohapel P, Araújo IM, Popovic N, Li J-Y, Brundin P, Petersén Å (2005) Reduced hippocampal neurogenesis in $R 6 / 2$ transgenic Huntington's disease mice. Neurobiol Dis 20:744-751.

Giralt A, Saavedra A, Carretón O, Arumí H, Tyebji S, Alberch J, Pérez-Navarro E (2013) PDE10 inhibition increases GluA1 and CREB phosphorylation and improves spatial and recognition memories in a Huntington's disease mouse model: PDE10 inhibition improves cognition in Huntington's disease. Hippocampus 23:684-695.

Gonçalves JT, Schafer ST, Gage FH (2016) Adult neurogenesis in the hippocampus: from stem cells to behavior. Cell 167:897-914.

Grajkowska LT, Ceribelli M, Lau CM, Warren ME, Tiniakou I, Nakandakari Higa S, Bunin A, Haecker H, Mirny LA, Staudt LM, Reizis B (2017) Isoform-specific expression and feedback regulation of E protein TCF4 control dendritic cell lineage specification. Immunity 46:65-77.

Grima JC, Daigle JG, Arbez N, Cunningham KC, Zhang K, Ochaba J, Geater C, Morozko E, Stocksdale J, Glatzer JC, Pham JT, Ahmed I, Peng Q, Wadhwa H, Pletnikova O, Troncoso JC, Duan W, Snyder SH, Ranum LPW, Thompson LM, et al. (2017) Mutant huntingtin disrupts the nuclear pore complex. Neuron 94:93-107.e6.

Harris KL, Armstrong M, Swain R, Erzinclioglu S, Das T, Burgess N, Barker RA, Mason SL (2019) Huntington's disease patients display progressive deficits in hippocampal-dependent cognition during a task of spatial memory. Cortex 119:417-427.

Hensman Moss DJ, Flower MD, Lo KK, Miller JRC, van Ommen GJB, 't Hoen PAC, Stone TC, Guinee A, Langbehn DR, Jones L, Plagnol V, van Roon-Mom WMC, Holmans P, Tabrizi SJ (2017) Huntington's disease blood and brain show a common gene expression pattern and share an immune signature with Alzheimer's disease. Sci Rep 7:44849.

Jung M, Häberle BM, Tschaikowsky T, Wittmann M-T, Balta E-A, Stadler V-C, Zweier C, Dörfler A, Gloeckner CJ, Lie DC (2018) Analysis of the expression pattern of the schizophrenia-risk and intellectual disability gene TCF4 in the developing and adult brain suggests a role in development and plasticity of cortical and hippocampal neurons. Mol Autism 9:20.

Kalscheuer VM, Feenstra I, Van Ravenswaaij-Arts CMA, Smeets DFCM, Menzel C, Ullmann R, Musante L, Ropers H-H (2008) Disruption of the TCF4 gene in a girl with mental retardation but without the classical Pitt-Hopkins syndrome. Am J Med Genet A 146A:2053-2059.

Kannike K, Sepp M, Zuccato C, Cattaneo E, Timmusk T (2014) Forkhead transcription factor FOXO3a levels are increased in Huntington disease because of overactivated positive autofeedback loop. J Biol Chem 289:32845-32857.

Kennedy AJ, Rahn EJ, Paulukaitis BS, Savell KE, Kordasiewicz HB, Wang J, Lewis JW, Posey J, Strange SK, Guzman-Karlsson MC, Phillips SE, Decker K, Motley ST, Swayze EE, Ecker DJ, Michael TP, Day JJ, Sweatt JD (2016) Tcf4 regulates synaptic plasticity, DNA methylation, and memory function. Cell Rep 16:2666-2685.

Kim H, Berens NC, Ochandarena NE, Philpot BD (2020) Region and cell type distribution of TCF4 in the postnatal mouse brain. Front Neuroanat 14:42.

Langfelder P, Cantle JP, Chatzopoulou D, Wang N, Gao F, AlRamahi I, Lu XH, Ramos EM, El-Zein K, Zhao Y, Deverasetty S, Tebbe A, Schaab C, Lavery DJ, Howland D, Kwak S, Botas J, Aaronson JS, Rosinski J, Coppola G, et al. (2016) Integrated genomics and proteomics define huntingtin CAG length-dependent networks in mice. Nat Neurosci 19:623-633.
Lazic SE, Grote H, Armstrong RJE, Blakemore C, Hannan AJ, van Dellen A, Barker RA (2004) Decreased hippocampal cell proliferation in R6/1 Huntington's mice. Neuroreport 15:811-813.

Li H, Zhu Y, Morozov YM, Chen X, Page SC, Rannals MD, Maher BJ, Rakic P (2019) Disruption of TCF4 regulatory networks leads to abnormal cortical development and mental disabilities. Mol Psychiatry 24:1235-1246.

Liu Y, Ray SK, Yang X-Q, Luntz-Leybman V, Chiu I-M (1998) A splice variant of E2-2 basic helix-loop-helix protein represses the brainspecific fibroblast growth factor 1 promoter through the binding to an imperfect E-box. J Biol Chem 273:19269-19276.

Luthi-Carter R, Hanson SA, Strand AD, Bergstrom DA, Chun W, Peters NL, Woods AM, Chan EY, Kooperberg C, Krainc D, Young AB, Tapscott SJ, Olson JM (2002) Dysregulation of gene expression in the R6/2 model of polyglutamine disease: parallel changes in muscle and brain. Hum Mol Genet 11:1911-1926.

Lynch G, Kramar EA, Rex CS, Jia Y, Chappas D, Gall CM, Simmons DA (2007) Brain-derived neurotrophic factor restores synaptic plasticity in a knock-in mouse model of Huntington's disease. J Neurosci 27:4424-4434.

Mansvelder HD, Verhoog MB, Goriounova NA (2019) Synaptic plasticity in human cortical circuits: cellular mechanisms of learning and memory in the human brain? Curr Opin Neurobiol 54:186193.

Mangiarini L, Sathasivam K, Seller M, Cozens B, Harper A, Hetherington C, Lawton M, Trottier Y, Lehrach H, Davies SW, Bates GP (1996) Exon 1 of the HD gene with an expanded CAG repeat Is sufficient to cause a progressive neurological phenotype in transgenic mice. Cell 87:493-506.

Massari ME, Murre C (2000) Helix-loop-helix proteins: regulators of transcription in eucaryotic organisms. Mol Cell Biol 20:429-440.

McClelland JL, McNaughton BL, O'Reilly RC (1995) Why there are complementary learning systems in the hippocampus and neocortex: insights from the successes and failures of connectionist models of learning and memory. Psychol Rev 102:419-457.

McColgan P, Tabrizi SJ (2018) Huntington's disease: a clinical review. Eur J Neurol 25:24-34.

Milnerwood AJ, Cummings DM, Dallérac GM, Brown JY, Vatsavayai SC, Hirst MC, Rezaie P, Murphy KPSJ (2006) Early development of aberrant synaptic plasticity in a mouse model of Huntington's disease. Hum Mol Genet 15:1690-1703.

Miyata T, Maeda T, Lee JE (1999) NeuroD is required for differentiation of the granule cells in the cerebellum and hippocampus. Genes Dev 13:1647-1652.

Naver B, Stub C, Møller M, Fenger K, Hansen AK, Hasholt L, Sørensen SA (2003) Molecular and behavioral analysis of the r6/1 Huntington's disease transgenic mouse. Neuroscience 122:10491057.

Neueder A, Bates GP (2014) A common gene expression signature in Huntington's disease patient brain regions. BMC Med Genomics 7:60.

Page SC, Hamersky GR, Gallo RA, Rannals MD, Calcaterra NE, Campbell MN, Mayfield B, Briley A, Phan BN, Jaffe AE, Maher BJ (2018) The schizophrenia- and autism-associated gene, transcription factor 4 regulates the columnar distribution of layer $2 / 3$ prefrontal pyramidal neurons in an activity-dependent manner. Mol Psychiatry 23:304-315.

Park H, Poo M (2013) Neurotrophin regulation of neural circuit development and function. Nat Rev Neurosci 14:7-23.

Persson P, Jögi A, Grynfeld A, Påhlman S, Axelson H (2000) HASH-1 and E2-2 are expressed in human neuroblastoma cells and form a functional complex. Biochem Biophys Res Commun 274:22-31.

Pleasure SJ, Collins AE, Lowenstein DH (2000) Unique expression patterns of cell fate molecules delineate sequential stages of dentate gyrus development. J Neurosci 20:6095-6105.

Pouladi MA, Morton AJ, Hayden MR (2013) Choosing an animal model for the study of Huntington's disease. Nat Rev Neurosci 14:708-721.

Puigdellívol M, Saavedra A, Pérez-Navarro E (2016) Cognitive dysfunction in Huntington's disease: mechanisms and therapeutic 
strategies beyond BDNF: cognitive dysfunction in HD. Brain Pathol 26:752-771.

Quirion JG, Parsons MP (2019) The onset and progression of hippocampal synaptic plasticity deficits in the Q175FDN mouse model of Huntington disease. Front Cell Neurosci 13:326.

Ramirez-Garcia G, Galvez V, Diaz R, Bayliss L, Fernandez-Ruiz J, Campos-Romo A (2020) Longitudinal atrophy characterization of cortical and subcortical gray matter in Huntington's disease patients. Eur J Neurosci 51:1827-1843.

Schoof M, Hellwig M, Harrison L, Holdhof D, Lauffer MC, Niesen J, Virdi S, Indenbirken D, Schüller U (2020) The basic helix-loop-helix transcription factor TCF4 impacts brain architecture as well as neuronal morphology and differentiation. Eur J Neurosci 51:22192235.

Sepp M, Kannike K, Eesmaa A, Urb M, Timmusk T (2011) Functional diversity of human basic helix-loop-helix transcription factor TCF4 isoforms generated by alternative $5^{\prime}$ exon usage and splicing. PLoS One 6:e22138.

Sepp M, Pruunsild P, Timmusk T (2012) Pitt-Hopkins syndrome-associated mutations in TCF4 lead to variable impairment of the transcription factor function ranging from hypomorphic to dominantnegative effects. Hum Mol Genet 21:2873-2888.

Sepp M, Vihma H, Nurm K, Urb M, Page SC, Roots K, Hark A, Maher BJ, Pruunsild P, Timmusk T (2017) The intellectual disability and schizophrenia associated transcription factor TCF4 is regulated by neuronal activity and protein kinase A. J Neurosci 37:1051610527.

Siebzehnrübl FA, Raber KA, Urbach YK, Schulze-Krebs A, Canneva F, Moceri S, Habermeyer J, Achoui D, Gupta B, Steindler DA, Stephan M, Nguyen HP, Bonin M, Riess O, Bauer A, Aigner L, Couillard-Despres S, Paucar MA, Svenningsson P, Osmand A, et al. (2018) Early postnatal behavioral, cellular, and molecular changes in models of Huntington disease are reversible by HDAC inhibition. Proc Natl Acad Sci USA 115:E8765-E8774.

Simpson JM, Gil-Mohapel J, Pouladi MA, Ghilan M, Xie Y, Hayden MR, Christie BR (2011) Altered adult hippocampal neurogenesis in the YAC128 transgenic mouse model of Huntington disease. Neurobiol Dis 41:249-260.

Skerjanc IS, Truong J, Filion P, McBurney MW (1996) A splice variant of the ITF-2 transcript encodes a transcription factor that inhibits MyoD activity. J Biol Chem 271:3555-3561.

Smith-Dijak AI, Sepers MD, Raymond LA (2019) Alterations in synaptic function and plasticity in Huntington disease. J Neurochem 150:346-365.

Stout JC, Paulsen JS, Queller S, Solomon AC, Whitlock KB, Campbell JC, Carlozzi N, Duff K, Beglinger LJ, Langbehn DR, Johnson SA, Biglan KM, Aylward EH; The PREDICT-HD Investigators and Coordinators of the Huntington Study Group (2011) Neurocognitive signs in prodromal Huntington disease. Neuropsychology 25:1-14.

Sugars KL, Rubinsztein DC (2003) Transcriptional abnormalities in Huntington disease. Trends Genet 19:233-238.

Tamberg L, Jaago M, Säälik K, Sirp A, Tuvikene J, Shubina A, Kiir CS, Nurm K, Sepp M, Timmusk T, Palgi M (2020) Daughterless, the Drosophila orthologue of TCF4, is required for associative learning and maintenance of the synaptic proteome. Dis Model Mech 13:dmm042747.

Tereshchenko AV, Schultz JL, Bruss JE, Magnotta VA, Epping EA, Nopoulos PC (2020) Abnormal development of cerebellar-striatal circuitry in Huntington disease. Neurology 94:e1908-e1915.
Thaxton C, Kloth AD, Clark EP, Moy SS, Chitwood RA, Philpot BD (2018) Common pathophysiology in multiple mouse models of Pitt-Hopkins syndrome. J Neurosci 38:918-936.

The HD iPSC Consortium (2017) Developmental alterations in Huntington's disease neural cells and pharmacological rescue in cells and mice. Nat Neurosci 20:648-660.

The Huntington's Disease Collaborative Research Group (1993) A novel gene containing a trinucleotide repeat that is expanded and unstable on Huntington's disease chromosomes. Cell 72:971-983.

Tuvikene J, Esvald E-E, Rähni A, Uustalu K, Zhuravskaya A, Avarlaid A, Makeyev EV, Timmusk T (2021) Intronic enhancer region governs transcript-specific Bdnf expression in rodent neurons. Elife 10:e65161.

Valor LM (2015) Transcription, epigenetics and ameliorative strategies in Huntington's disease: a genome-wide perspective. Mol Neurobiol 51:406-423.

van der Plas E, Langbehn DR, Conrad AL, Koscik TR, Tereshchenko A, Epping EA, Magnotta VA, Nopoulos PC (2019) Abnormal brain development in child and adolescent carriers of mutant huntingtin. Neurology 93:e1021-e1030.

Wang Y, Lu Z, Zhang Y, Cai Y, Yun D, Tang T, Cai Z, Wang C, Zhang Y, Fang F, Yang Z, Behnisch T, Xie Y (2020) Transcription factor 4 safeguards hippocampal dentate gyrus development by regulating neural progenitor migration. Cereb Cortex 30:3102-3115.

Wedel M, Fröb F, Elsesser O, Wittmann M-T, Lie DC, Reis A, Wegner $M(2020)$ Transcription factor Tcf4 is the preferred heterodimerization partner for Olig2 in oligodendrocytes and required for differentiation. Nucleic Acids Res 48:4839-4857.

Zhai W, Jeong H, Cui L, Krainc D, Tjian R (2005) In vitro analysis of huntingtin-mediated transcriptional repression reveals multiple transcription factor targets. Cell 123:1241-1253.

Zhang Y, Li M, Drozda M, Chen M, Ren S, Mejia Sanchez RO, Leavitt BR, Cattaneo E, Ferrante RJ, Hayden MR, Friedlander RM (2003) Depletion of wild-type huntingtin in mouse models of neurologic diseases: depletion of huntingtin in neurologic diseases. $J$ Neurochem 87:101-106.

Zuccato C, Cattaneo E (2014) Normal function of huntingtin. Oxford: Oxford University Press.

Zuccato C, Ciammola A, Rigamonti D, Leavitt BR, Goffredo D, Conti L, MacDonald ME, Friedlander RM, Silani V, Hayden MR, Timmusk T, Sipione S, Cattaneo E (2001) Loss of huntingtin-mediated BDNF gene transcription in Huntington's disease. Science 293:493-498.

Zuccato C, Tartari M, Crotti A, Goffredo D, Valenza M, Conti L, Cataudella T, Leavitt BR, Hayden MR, Timmusk T, Rigamonti D, Cattaneo E (2003) Huntingtin interacts with REST/NRSF to modulate the transcription of NRSE-controlled neuronal genes. Nat Genet 35:76-83.

Zuccato C, Belyaev N, Conforti P, Ooi L, Tartari M, Papadimou E, MacDonald M, Fossale E, Zeitlin S, Buckley N, Cattaneo E (2007) Widespread disruption of repressor element-1 silencing transcription factor/neuron-restrictive silencer factor occupancy at its target genes in Huntington's disease. J Neurosci 27:6972-6983.

Zweier C, Peippo MM, Hoyer J, Sousa S, Bottani A, Clayton-Smith J, Reardon W, Saraiva J, Cabral A, Gohring I, Devriendt K, de Ravel T, Bijlsma EK, Hennekam RCM, Orrico A, Cohen M, Dreweke A, Reis A, Nurnberg P, Rauch A (2007) Haploinsufficiency of TCF4 causes syndromal mental retardation with intermittent hyperventilation (Pitt-Hopkins syndrome). Am J Hum Genet 80:994-1001. 